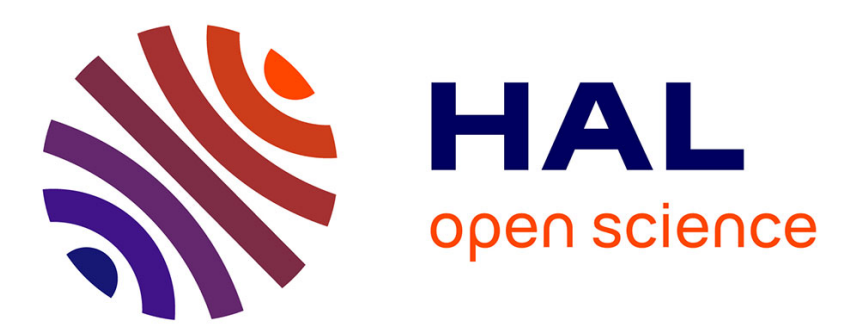

\title{
Impacts zootechnique et socio-économique potentiels d'une éventuelle utilisation de la rtGH en salmoniculture
}

Gérard Maisse, Francois Bonnieux, Benoit Fauconneau, André Fauré, Yoann

Gloaguen, Pierre-Yves Le Bail, Patrick Prunet, Pierre Rainelli

\section{- To cite this version:}

Gérard Maisse, Francois Bonnieux, Benoit Fauconneau, André Fauré, Yoann Gloaguen, et al.. Impacts zootechnique et socio-économique potentiels d'une éventuelle utilisation de la rtGH en salmoniculture. Productions Animales, 1993, 6 (3), pp.167-183. 10.20870/productions-animales.1993.6.3.4197 . hal02715113

\section{HAL Id: hal-02715113 \\ https://hal.inrae.fr/hal-02715113}

Submitted on 1 Jun 2020

HAL is a multi-disciplinary open access archive for the deposit and dissemination of scientific research documents, whether they are published or not. The documents may come from teaching and research institutions in France or abroad, or from public or private research centers.
L'archive ouverte pluridisciplinaire HAL, est destinée au dépôt et à la diffusion de documents scientifiques de niveau recherche, publiés ou non, émanant des établissements d'enseignement et de recherche français ou étrangers, des laboratoires publics ou privés. 
INRA Prod. Anim., 1993, 6 (3), 167 - 183.
G. MAISSE, F. BONNIEUX*, B. FAUCONNEAU $U^{* * *}$, A. FAURE, Y. GLOAGUEN* ${ }^{*}$, P.Y. LE BAIL ${ }^{* *}$, P. PRUNET T**, P. RAINELLI*

INRA GEDITH, Département d'Hydrobiologie, 35042 Rennes Cedex

*INRA Station d'Economie et Sociologie Rurales, 35042 Rennes Cedex

**INRA Laboratoire de Physiologie des Poissons, 35042 Rennes Cedex

\section{Impacts}

zootechnique et socio-économique potentiels d'une éventuelle utilisation de la rtGH en salmoniculture

\section{La rtGH présente des potentialités non négligeables pour la salmoniculture : meilleure utilisation des matières premières, diminution des rejets, tout autant que des risques : mauvaise image du produit, surproduction, impact sur la structure de la profession.}

L'aquaculture des salmonidés (truites et saumons) est la principale production piscicole de l'Europe de l'ouest. La production de truites, se fait en très grande majorité dans les eaux continentales des pays de la CEE (143600 t en 1989) (Gabriel 1990). Elle concerne surtout l'espèce "Arc-en-ciel", la truite Fario et l'omble de fontaine ne représentant respectivement que $2,4 \%$ et $0,9 \%$ de la production. Les Etats Unis d'Amérique $(40000 \mathrm{t})$ et le Japon $(20000 \mathrm{t})$ sont des producteurs importants qui n'ont cependant pas d'impact sur le marché européen. Le calibre de vente est en majorité la truite portion d'environ $200 \mathrm{~g}$. Cependant la dernière décennie a vu apparaître sur le marché des tailles plus importantes, $700 \mathrm{~g}$ pour la production de filets portion, et $2 \mathrm{~kg}$ pour la grosse truite. Ces animaux sont alors produits soit en eau douce, c'est le cas de la France, soit en mer, c'est le cas des pays producteurs de saumons.

\section{Résumé}

Les salmonidés (Truite et Saumon) sont la principale production piscicole de l'Europe de l'ouest. Les biotechnologies animales intéressant la salmoniculture relèvent de trois domaines : les manipulations génétiques (la triploïdie pour la production de poissons stériles), le transfert de gène (pour produire des poissons résistants aux maladies infectieuses) et les peptides recombinants (vaccins recombinants contre les maladies virales, l'hormone de croissance recombinante de truite -rtGH-).

La rtGH a deux effets biologiques principaux : une stimulation de la croissance, en particulier en eau froide, et une amélioration de l'adaptation des juvéniles à l'eau de mer. Un traitement chronique avec la rtGH peut accroître de manière substantielle la production des principaux types de pisciculture. Cependant, il ne peut être réellement pratiqué que dans les exploitations, ayant une haute technicité, qui pratiquent l'oxygénation de l'eau, le contrôle photopériodique de la date de ponte et la gestion informatisée des stocks de poissons. Une simulation des effets d'un traitement par une injection unique de rtGH, pour préparer les juvéniles de Saumon au transfert en mer, montre que le transfert automnal de jeunes saumons traités modifie la période de vente sans augmenter la production. Cependant, si le pisciculteur transfère un premier groupe de poissons traités en automne et un second groupe de poissons naturellement adaptés (smolts) au printemps, la production augmente de $20 \%$ et, plus important, la période de vente est allongée.

La rentabilité de la production de truites portion semble renforcée et, en considérant uniquement la phase de production, il ne semble pas que la diversification vers le filet ou la grosse truite améliore la rentabilité des piscicultures. L'adoption de la rtGH devrait, à long terme, se traduire par des bénéfices collectifs partagés par les producteurs et les consommateurs. Cependant la phase transitoire est délicate et la voie est très étroite entre la réussite et le rejet. Ce dernier entraînerait une restructuration complète de la branche. La stratégie de la réussite semble bien passer par la diversification et l'amélioration de l'image de marque. Même dans ce cas on peut s'attendre à des effets sur la structure de la branche, certains producteurs bénéficiant plus que d'autre du surplus.

Si l'on prend aussi en compte la notion de besoin, la rtGH présente des potentialités non négligeables pour la salmoniculture (meilleure utilisation des matières premières, diminution des rejets) tout autant que des risques (mauvaise image du produit, surproduction, impact sur la structure de la profession). Dans la mesure où son innocuité serait prouvée, la mise en oeuvre de cet outil devrait être progressive, concertée avec les producteurs, et s'accompagner de mesure en faveur de la qualité (label). 
Comme le montrent les résultats d'une enquête menée par l'institut de sondage CSA pour le compte de la Fédération Française de l'Aquaculture (tableau 1), le filet portion frais se situe sur le même créneau commercial que la truite portion et pourrait à terme prendre une part importante de ce marché.

Les plus importants producteurs de la CEE sont la France (36000 t), l'Italie (30000 t), le Danemark (23000 t), la République Fédérale Allemande (17000t), l'Espagne (16600 t) et le Royaume-Uni $(16600 \mathrm{t})$. Cette activité reste relativement jeune, puisqu'elle a connu son véritable démarrage au milieu des années soixante avec l'apparition de l'alimentation artificielle sous forme de granulés secs. Les dix dernières années ont vu le niveau technologique des exploitations s'élever, phénomène qui s'accentue avec le renouvellement des cadres des exploitations et l'apport de nouveaux capitaux. Ainsi, bien que la règlementation soit de plus en plus contraignante, la production de truites portion de la CEE est passée de 84500 t en 1980 à 136000 t en 1989 .

La production mondiale de saumons d'élevage a été multipliée, durant la même période, par 32 , passant de $7200 \mathrm{t}$ en 1980 à $229200 \mathrm{t}$ en 1989 (rapporté par Haffray et al 1990). Cette augmentation a concerné en particulier la CEE, dont la production est passée de $650 \mathrm{t}$ en 1980 à 40600 t (dont 33000 t par le Royaume-Uni, essentiellement Ecosse) en 1989. Le premier producteur mondial de saumon d'élevage est aujourd'hui la Norvège avec 150000 t (la production norvégienne a presque doublé entre 1988 et 1989 , passant de $80000 \mathrm{t}$ à 150000 t). Cette réussite technique s'est malheureusement transformée en catastrophe économique (Fish Farming International, 1991, vol $18, n^{\circ} 12$ ) le marché n'ayant pu suivre cette augmentation exponentielle. Il est probable que, dans les prochaines années, la production norvégienne revienne à un niveau voisin de $100000 \mathrm{t}$. L'Europe de l'ouest produit $190000 \mathrm{t}$ de saumon atlantique, alors que le Canada en produit 3200 , et que le reste de la production mondiale (55000 t) concerne les saumons du Pacifique produits par le Canada, les USA, le Chili, le Japon et la Nouvelle Zélande. Il faut préciser que le saumon d'élevage est en concurrence sur le marché avec environ $630000 \mathrm{t}$ de saumons (essentiellement du Pacifique) débarqués par la pêche (Haffray et al 1990). Le marché mondial doit donc absorber $850000 \mathrm{t}$ de saumons, ce qui ne va pas sans poser de nombreux problèmes. Ainsi, la Norvège, dont plus de $90 \%$ de la pro-

Tableau 1. Habitude de consommation de la truite en France (base : acheteur de chaque type de truite; plusieurs réponses possibles) - sondage CSA (Suquet 1991)

\begin{tabular}{|lcccc|}
\hline & $\begin{array}{c}\text { repas de } \\
\text { semaine }\end{array}$ & $\begin{array}{c}\text { repas du } \\
\text { week-end }\end{array}$ & $\begin{array}{c}\text { avec des } \\
\text { invités }\end{array}$ & fêtes \\
portion fraîche & $44 \%$ & $25 \%$ & $30 \%$ & $11 \%$ \\
filet frais & $44 \%$ & $26 \%$ & $29 \%$ & $11 \%$ \\
grande fraîche & $34 \%$ & $36 \%$ & $57 \%$ & $18 \%$ \\
fumée & $15 \%$ & $28 \%$ & $49 \%$ & $43 \%$ \\
\hline
\end{tabular}

duction est exporté, doit stocker en congélateurs près de 40000 t de saumons (Fish Farming International, 1991 , vol. $\left.18, \mathrm{n}^{\circ} 1\right)$, tout en détruisant 20 millions de smolts (juvéniles de saumons prêts à être transférés en mer) sur 70 millions produits (Fish Farming International, 1991, vol. $18, \mathrm{n}^{\circ} 6$ ).

La recherche n'a pas été étrangère au développement de la salmoniculture, ainsi la mise au point, dans les années "soixante", de l'alimentation artificielle à base de granulés secs marqua-t-il le début de la salmoniculture moderne. Comme pour les autres élevages d'intérêt agronomique, les recherches en nutrition, reproduction, génétique, pathologie, etc, se développèrent et contribuèrent à l'industrialisation de la filière. Aujourd'hui, l'essor des biotechnologies suscite à la fois espoirs et craintes.

Les biotechnologies (au sens restrictif d'ingéniérie génétique appliquée soit aux animaux élevés soit à des micro-organismes produisant des peptides recombinants - voir Houdebine 1991) présentant un intérêt potentiel en salmoniculture relèvent de trois domaines :

\section{- Les manipulations génétiques}

L'induction de la polyploïdie est possible chez les salmonidés en faisant subir aux oeufs un choc thermique ou un choc de pression dans les minutes suivant la fécondation, (triploïdie) ou au moment de la première division cellulaire (tétraploïdie) (Chourrout 1984). D'un point de vue piscicole, les individus triploïdes sont particulièrement intéressants pour deux raisons :

a / Ils sont stériles et, par conséquent, ne présentent pas les inconvénients liés à la maturation, pour le producteur de gros poissons (Chevassus et al 1984). En effet, au cours de la maturation, les individus normaux, marquent un arrêt de croissance et leur chair perd ses qualités organoleptiques suite à la diminution de la teneur en lipides. Chez les individus triploides, les femelles conservent toute leur vie les caractéristiques de poissons immatures, alors que les mâles maturent, mais ne sont pas fonctionnels. Il est bien évident que seules les femelles intéressent les éleveurs et qu'en conséquence cette technique doit être associée à celle du monosexage femelle. Par ailleurs la spécialisation des pisciculteurs et notamment l'apparition de sélectionneurs renforcera encore l'intérêt de cette technique qui permettra aisément au sélectionneur de protéger la souche obtenue en ne vendant que des oeufs triploïdes donnant des individus stériles.

b / La triploïdie permet d'obtenir des hybrides viables en grand nombre, alors que les hybrides diploïdes subissent des mortalités très importantes rendant leur exploitation piscicole impensable. Ces hybrides triploïdes sont particulièrement intéressants pour la production de poissons résistants à certaines maladies virales; c'est le cas de l'hybride triploïde obtenu par croisement entre des mâles de saumon coho et des femelles de truite arc-en-ciel qui est résistant à la septicémie hémorragique virale comme le saumon coho alors que la truite arc en ciel y est extrêmement sensible (Dorson et Chevassus 1984). 
$\mathrm{Au}$ niveau des élevages européens la technique de triploïdisation est aujourd'hui maîtrisée par la plupart des grandes entreprises.

\section{- Le transfert de gène}

Le transfert de gène chez les salmonidés en est à ses débuts, puisque les premiers travaux publiés sont ceux de Chourrout et al (1986), concernant l'injection de cDNA d'hormone de croissance humaine dans le cytoplasme d'oeufs de truite fraîchement fécondés. La persistance de l'ADN étranger est de type mosaique (on ne le retrouve pas dans toutes les cellules de l'animal) et l'expression est faible, voire nulle. Ces résultats sont cependant suffisamment prometteurs pour que les recherches se poursuivent avec comme objectif finalisé la production de poissons transgéniques résistants aux maladies infectieuses.

Il est probable que, pour des problèmes d'éthique et commerciaux, le développement de cette technique se fasse dans un nombre limité de centres de production qui ne distribueraient que des oeufs triploïdes donnant des individus stériles.

\section{- La production de peptides recombinants}

La production de peptides recombinants est une technique bien maîtrisée. Elle consiste à faire pénètrer le cDNA codant pour le peptide dans le génome d'un micro-organisme, puis à purifier le peptide produit. Cette technique peut permettre de produire en grande quantité des protéines dont la synthèse ou la purification à partir d'un gisement naturel restaient jusqu'ici d'un coût prohibitif. C'est aujourd'hui le cas des hormones de croissance recombinantes de salmonidés produites au Japon, aux U.S.A. et en Europe, à un niveau de recherche-développement (Le Bail et al 1992). L'hormone de croissance recombinante de truite arc-en-ciel est dénommée rtGH. Les projets futurs concernent la production de vaccins recombinants. Ces vaccins diffèreront des vaccins traditionnels mettant en oeuvre des agents pathogènes tués ou atténués, car seules les protéines ayant un effet immunogène seront utilisées. Ce procédé est particulièrement intéressant dans la prophylaxie virale. La production de protéines immunogènes de l'enveloppe du virus recombinantes est une voie qui est actuellement explorée pour la vaccination contre les principales maladies virales des salmonidés (Septicémie Hémorragique Virale, SHV, Nécrose Hématopoïétique Infectieuse, NHI, et Nécrose Pancréatique Infectieuse, NPI) et pour lesquelles les essais de vaccinations traditionnelles (virus tué ou atténué) n'ont pas abouti dans la pratique. Les premiers travaux (Gilmore et al 1988, Manning et Leong 1990) montrent qu'il est possible de développer une résistance à la NHI et la NPI chez des truites arc-en-ciel en les soumettant à un bain dans une solution d'extraits bactériens ( $E$. coli) contenant la protéine immunogène recombinante correspondante.

C'est donc dans ce contexte que se situe l'étude que nous avons réalisée pour la Commission des Communautés Européennes (DG XII SAST Project 4) qui désirait connaitre l'impact potentiel des biotechnologies en agriculture ; cette étude correspondait, en outre, à une attente de la profession, exprimée par la Fédération Européenne de Salmoniculture (Gabriel 1990) : "Des progrès de la biotechnologie et de la génétique pourraient venir de nouvelles solutions améliorant la productivité des piscicultures. Il n'est pas possible à ce jour d'évaluer l'impact qu'auront progressivement les nouvelles découvertes faites en la matière. L'on peut se demander aussi jusqu'à quel point ces nouvelles techniques ne nuiront pas à la bonne image de marque dont jouit la truite auprès du consommateur"

Cette interrogation est complétée par la remarque de Cordonnier (1989) qui, dans son étude sur l'impact économique de l'utilisation de la BST en élevage laitier, insiste sur le fait que "la conjonction de facteurs favorables fait apparaître des gains de productivité élevés propres à augmenter notablement le revenu de l'exploitant alors qu'une inadaptation de l'innovation à son contexte d'application peut avoir au contraire des conséquences dommageables, avec éventuellement apparition de marges nettes négatives."

L'étude que nous présentons ici repose sur une analyse bibliographique des effets biologiques de la somatotropine $(\mathrm{GH})$ - en particulier de la rtGH - chez les Salmonidés, suivie d'une simulation de ces effets sur la production des exploitations et du secteur, à partir de laquelle une analyse socio-économique a été réalisée afin d'évaluer l'impact potentiel de cette innovation.

\section{1 / Potentialités zootechniques de la rtGH : les aspects biologiques}

\section{1 / Qualité des rtGH disponibles}

Les préparations de GH, purifiées ou recombinantes, sont rarement composées d'une seule entité biochimique. Différentes formes qui existent à l'état naturel ou qui se forment au cours du protocole de préparation, les composent. Elles peuvent varier suivant la taille (monomères, polymères), la charge ou d'autres caractèristiques biochimiques (désaminées, phosphorylées, glycosilées...). Contrairement à ce qui a été observé chez les mammifères, les formes détectées semblent avoir des activités biologiques similaires chez la truite (Niu 1990, cité par Le Bail et al 1992).

Dans le cas de la rtGH produite par $E$. coli, la molécule n'a pas subi de maturation et sa structure tertiaire n'est pas conforme à celle de la GH naturelle. Sous cette forme, elle ne possède aucune activité de liaison à son récepteur tissulaire et donc aucune activité biologique. Il est donc nécessaire de procéder à une renaturation de la protéine recombinante de manière à lui donner une conformation tridimensionnelle conforme à celle de la molécule biologi- 
quement active, telle qu'elle se trouve naturellement chez l'animal. Cette étape, qui est en fait l'étape clef de la production par génie génétique, conditionne en grande partie la qualité des hormones recombinantes. Pour une GH de même origine zoologique (par exemple la truite), des techniques de production différentes peuvent conduire à des activités biologiques très différentes. Il est donc essentiel de caractériser et de quantifier les activités biologiques de ces hormones. Plusieurs techniques sont disponibles qui présentent des avantages et des inconvénients.

Les techniques immunologiques (dosage immuno-enzymatique - ELISA - et dosage radio-immunologique - RIA-), qui permettent une très bonne quantification de la $\mathrm{GH}$, ne mesurent pas l'activité biologique. Mais, dans le futur, l'utilisation d'anticorps monoclonaux reconnaissant spécifiquement le site actif de la GH, devrait permettre d'estimer l'activité biologique des préparations.

Il y a deux types de dosages biologiques : les tests in vivo et les tests in vitro. Le test in vitro est la transposition au poisson du "tibia test" classiquement utilisé pour caractériser les GH mammaliennes. Cette technique, lourde de mise en oeuvre, est progressivement abandonnée. On lui préfêre le test in vivo qui consiste à injecter à des animaux entiers ou hypophysectomisés, des préparations de GH et d'en mesurer les effets sur la croissance pondérale et linéaire. Cette technique présente plusieurs inconvénients majeurs : les effets sont peu quantifiables et peu reproductibles, les quantités injectées doivent être importantes et enfin le temps de réponse est long.

Le dosage par radiorécepteur constitue, à l'heure actuelle, l'outil le plus adapté pour mesurer l'activité biologique des $\mathrm{GH}$ de poissons. En effet, l'activité de liaison est une condition nécessaire et, dans la grande majorité des cas, suffisante pour l'obtention d'effets biologiques. Les résultats obtenus sont précis et répétables, la quantité d'hormone nécessaire est faible et la mise en oeuvre est simple. Cette technique a permis de mettre en évidence la grande variabilité de l'activité biologique des hormones de salmonidés actuellement disponibles. Il faut remarquer que, malheureusement, dans la très grande majorité des expériences mesurant les effets de la GH sur la physiologie des poissons, l'activité biologique des préparations hormonales n'était pas connue, car il n'existe pas de test biologique standardisé chez les poissons, alors qu'ils existent pour les hormones mammaliennes.

La substance active représente au moins $90 \%$ du produit obtenu après purification. La présence de contaminants nécessite la mise en place de tests toxicologiques qui n'ont pas révélé chez la truite de symptômes pour des doses correspondant à 1000 fois la dose active (J. Smal, communication personnelle). Il n'y a pas eu de test pratiqué chez des mammiferes ; seule information, l'absence de liaison entre la rtGH et les récepteurs à la $\mathrm{GH}$ humaine (P.-Y. Le Bail et al non publié).

\section{2 / Spécificité}

Si l'on considère l'ensemble des expériences de supplémentation avec des GH de différentes origines zoologiques effectuées chez les poissons (revue de Le Bail et al 1992), on constate que les GH mammaliennes sont actives chez toutes les espèces testées. De même, toutes les GH de poisson sont actives chez les espèces de poissons testées. Cependant, pour une même espèce cible, la truite par exemple, les différences d'activité biologique des GH d'origines zoologiques variées, peuvent être assez importantes. Ainsi les GH mammaliennes présentent une activité de liaison au récepteur hépatique de truite 30 fois plus faible que la rtGH. Cette différence est confirmée par les nombreuses expériences in vivo réalisées chez des Salmonidés, où les auteurs utilisent généralement 10 fois plus d'hormone mammalienne que de GH de Salmonidé. In vivo, les GH pisciaires d'origine autre que Salmonidés, sont généralement plus actives que les GH mammaliennes, mais également moins actives que la GH homologue. Le radiorécepteur confirme ces résultats : la rtGH est l'hormone de croissance la plus active chez les salmonidés.

$\mathrm{Au}$ vu de ces résultats, il apparaît que les GH de vertébrés ont des structures biochimiques similaires qui leur conferent une activité biologique de même type qui est confirmée par les dosages radiorécepteurs. Lorsque l'on recherche les similitudes de la structure primaire (séquence d'acides aminés) qui existent entre les GH d'origines zoologiques variées, les différences sont beaucoup plus nettes. Ainsi la GH humaine n'a qu'environ $30 \%$ d'homologie avec la $\mathrm{GH}$ de truite. Ces différences de structure biochimique se concrétisent par des différences immunologiques très marquées. Par exemple, les RIA de GH mammaliennes ne reconnaissent pas les $\mathrm{GH}$ pisciaires et réciproquement. De même les différentes GH de poissons ne sont reconnues que très partiellement dans les RIA de GH d'espèces n'appartenant pas à la même famille. L'utilisation d'une hormone hétérologue risque donc de provoquer une réaction immunitaire chez l'animal traité qui diminuerait l'efficacité du traitement, voire d'induire une auto-immunisation contre sa propre GH qui bloquerait sa croissance.

\section{3 / Effets métaboliques et cellulaires de la GH chez les poissons}

L'hormone de croissance semble à la fois augmenter l'appétit et améliorer l'efficacité de transformation des aliments (environ $20 \%$ ). Le métabolisme énergétique est stimulé, ce qui se traduit par une augmentation de la consommation post prandiale d'oxygène. Il y a cependant un changement dans l'utilisation energétique des substrats corporels des protéines et glucides alimentaires vers les lipides alimentaires (figure 1). Ces observations pourraient avoir des conséquences sur les besoins alimentaires des poissons traités (protéines de la ration et rapport protéine/énergie). 
La stimulation de l'utilisation des lipides par le poisson soumis à un traitement chronique à la GH est associée à une augmentation de la teneur en lipides du foie et une diminution du glycogène hépatique. Cette observation permet de suspecter une altération de la fonction hépatique, ce qui peut avoir des conséquences sur la résistance aux maladies des poissons traités, mais cela reste à étudier. Il est à noter toutefois qu'il a été montré qu'un traitement à la somatotropine ovine pouvait perturber certaines fonctions enzymatiques de la détoxification chez la truite (Cravédi et al 1991)

Figure 1. Effet de la supplémentation en somatotropine ovine (par implant intrapéritonéal) sur l'utilisation des substrats corporels (protéines, lipides, glucides) estimée par calorimètrie indirecte chez la truite arc-en-ciel ( $F$. Médale, non publié). Le lot $\mathrm{GH} 1$ a été nourri avec le même taux de rationnement que les témoins, le lot $\mathrm{GH} 2$ a été nourri ad libitum.

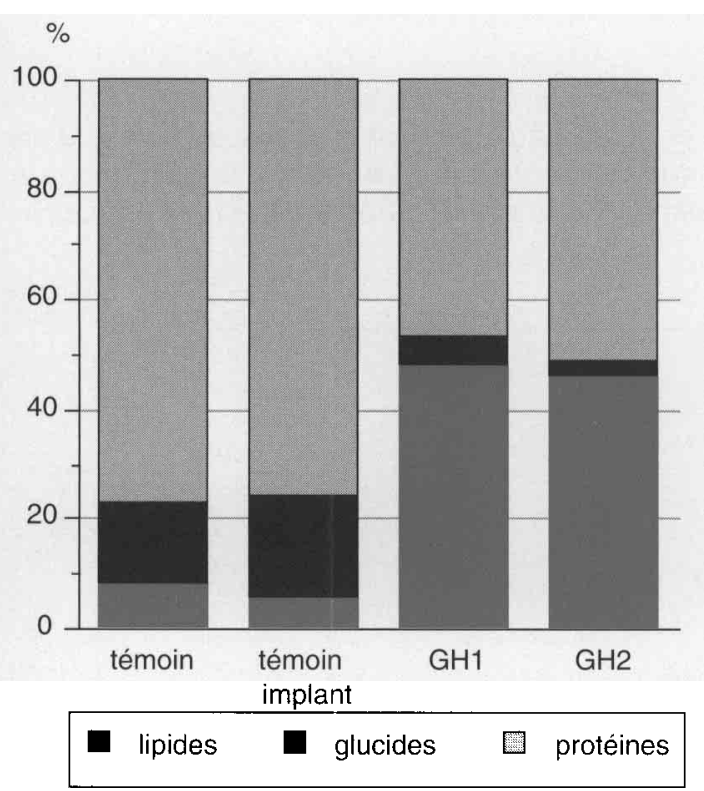

L'utilisation des protéines alimentaires est augmentée à la fois par la stimulation de la synthèse protéique dans de nombreux tissus y compris le muscle, et par une réduction ( $20 \%$ ) de l'excrétion azotée (figure 2). Les conséquences sur la réduction de l'azote soluble (ammoniaque) dans les effluents de la pisciculture sont alors très importantes.

Des modifications des tissus sont observées au niveau cellulaire en raison des effets classiques de la GH sur la division cellulaire. Par exemple, la proportion des petites fibres musculaires augmente (figure 3), cependant on ne sait pas dans quelle mesure la fonction locomotrice du muscle et la qualité de la chair sont affectées.

Les dépots lipidiques sont diminués et la teneur de la chair en lipides est nettement inférieure chez les poissons traités. Certaines caractéristiques physiques, qui sont généralement associées avec la teneur lipidique de la chair, pourraient être altérées comme la cou-
Figure 2. Effet de la supplémentation en somatotropine ovine (par implant intrapéritonéal) sur la rétention et les pertes azotées chez la truite arc-en-ciel (F. Médale, non publié). Les lots sont les mêmes que dans la figure 1.

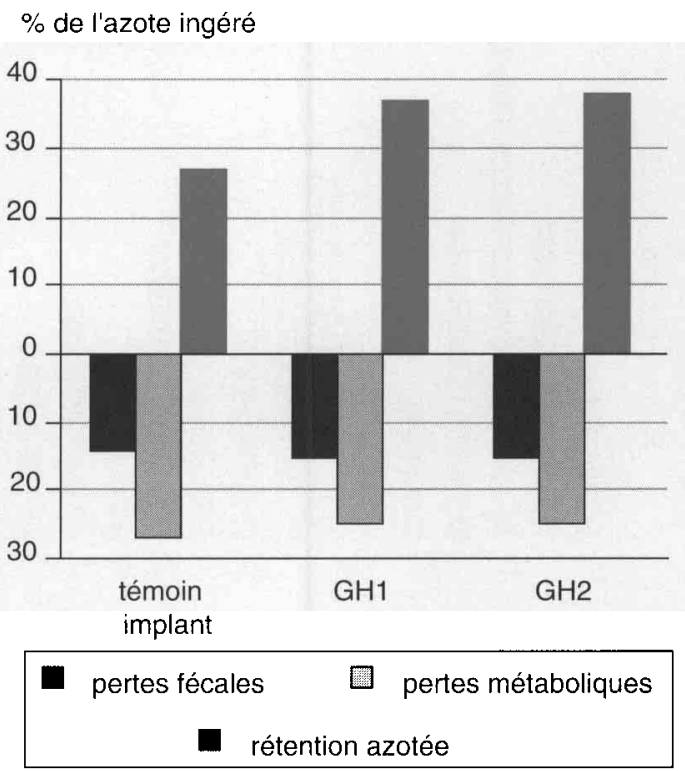

leur ou la texture. De même, la qualité du poisson fumé pourrait être plus affectée en raison de la baisse de la teneur en lipides de la chair. Il est important de préciser que l'augmentation concomitante de la teneur en eau du muscle n'est pas associée avec une diminution de la capacité de rétention de l'eau par la chair (B. Fauconneau et M. Laroche, non publié). Cependant des informations supplémentaires sont nécessaires pour avoir une idée précise des effets de la GH sur la qualité de la chair.

\section{4 / La stimulation de la croissance : variabilité de la réponse à un traitement chronique}

La dose de GH injectée est le facteur qui influence le plus la réponse au traitement. Les doses efficaces les plus faibles avoisinent 0,1 microgrammes par gramme de poids vif et par semaine avec les GH homologues. Au delà de certaines doses ( 1 microgramme pour la $\mathrm{GH}$ homologue ou 10 microgrammes pour les $\mathrm{GH}$ mammaliennes), les effets ne sont plus augmentés. La mauvaise maîtrise des techniques d'administration de l'hormone ne permet pas de connaître avec précision la quantité d'hormone et le temps maximum de traitement réellement efficace.

En dehors de la dose, le facteur qui influe le plus sur la réponse à un traitement à la rtGH est la température d'élevage (figure 4). L'analyse de l'ensemble des données disponibles sur les salmonidés montre que le traitement est d'autant plus efficace que la température est basse (Le Bail et al 1992). Cette observation présente un très grand intérêt pratique puisque c'est justement à ces basses tempéra-

\author{
Chez les poissons \\ traités à la GH, \\ l'utilisation des \\ lipides est stimulée \\ et la synthèse \\ protéique accrue. \\ Cela conduit à une \\ diminution de la \\ teneur en lipides du \\ poisson et à une \\ réduction de la \\ teneur en azote des \\ effluents de \\ pisciculture.
}


Figure 3. Distribution de la taille des fibres du muscle blanc chez la truite arc-en-ciel supplémentée en somatotropine humaine par injections bihebdomadaires (Fauconneau et al 1991).

Effectif par classe (en \% du total)

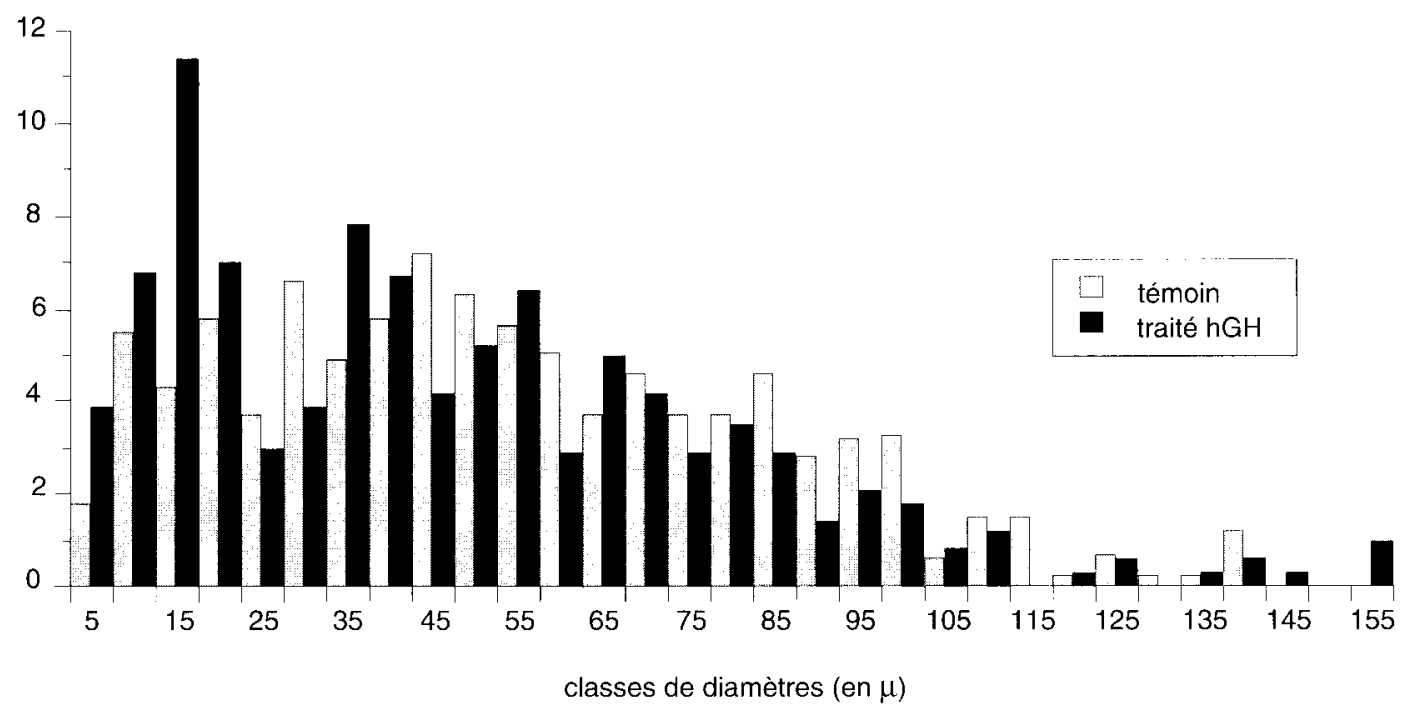

Figure 4. Analyse factorielle des correspondances effectuée à partir des données de la littérature rapportant les résultats d'expérimentations de supplémentation avec de la somatotropine. L'augmentation de l'indice $(1,2, \ldots)$ indique un accroissement de la valeur du paramètre (d'après Le Bail et al 1992).

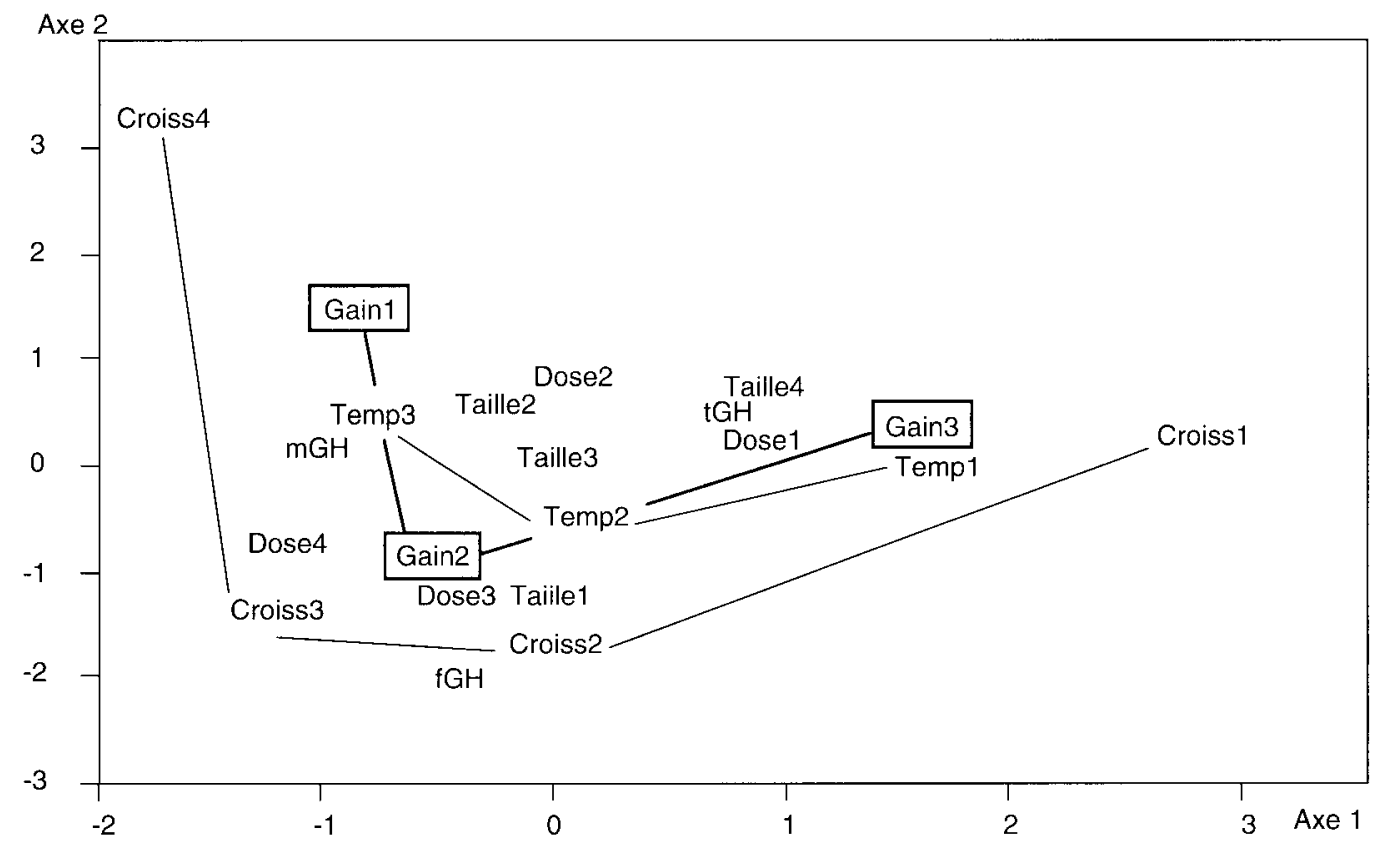

\footnotetext{
Le traitement à la GH a des effets favorables sur le transfert des poissons en mer : la mortalité posttransfert diminue et le déséquilibre de la balance hydrominérale consécutif au transfert est réduit.
}

tures que la croissance est la plus lente naturellement. Toutes les piscicultures d'eau froide sont donc potentiellement intéressées par un tel traitement.
Des différences de réponse à un traitement à la $\mathrm{GH}$, non négligeables, peuvent être observées suivant les souches génétiques de truite arc-en-ciel. En effet, dans des conditions d'éle- 
vage identiques, certaines souches peuvent avoir des gains de croissance, dus à la $\mathrm{GH}$, multipliés par 2 ou 3 par rapport à d'autres souches (P.-Y. Le Bail, non publié). Il est vraisemblable que certaines espèces de poissons, ayant fait l'objet d'un faible effort de sélection, soient plus sensibles que d'autres, comme cela a été observé chez les mammifères. On sait, par ailleurs, qu'à facteur externe constant, le taux de croissance d'une population de truites n'est pas constant, mais qu'il subit des variations rythmiques. Un traitement à la $\mathrm{GH}$ n'élimine pas ces rythmes mais a tendance à les amortir ; les gains dus à la GH sont supérieurs durant les périodes de faible taux de croissance et moindres lors des périodes de taux de croissance maximal. L'effet d'un traitement GH n'est donc pas constant au cours du temps.

\section{5 / Préparation du poisson au passage en mer}

Les populations naturelles de salmonidés peuvent être classées en deux groupes : les espèces ou variétés subissant de profondes modifications physiologiques (smoltification) se concluant par une migration active en mer et les espèces ou variétés, dites sédentaires, d'eau douce présentant des capacités plus ou moins développées de s'adapter au milieu marin.

L'élevage intensif des espèces à smoltification (saumon) implique de réaliser une partie du cycle d'élevage en mer. Pour les espèces sédentaires (truite arc-en-ciel, truite fario), les essais d'élevage en mer ont montré que ces conditions permettaient d'obtenir une meilleure croissance et un meilleur taux de conversion de l'aliment. Cependant cet effet positif de la salinité n'est observé que chez des poissons adaptés à leur environnement hyperosmotique.

La smoltification, phénomène complexe aboutissant à de nombreux changements de la physiologie, de la morphologie et du comportement du poisson (revue de Folmar et Dickhoff 1980) permet d'obtenir en eau douce un juvénile de saumon pré-adapté au passage en mer et au comportement migrateur. Actuellement, on arrive à produire des smolts après 15 mois d'élevage en eau douce, le transfert en mer ayant généralement lieu au printemps (Gaignon 1987).

Les capacités d'adaptation de la truite arcen-ciel ou de la truite fario sont dépendantes de la taille du poisson. On considère en général que la truite arc-en-ciel doit avoir un poids supérieur à 80-100 g ; la truite fario peut être transférée directement en eau de mer à un poids plus faible $(50 \mathrm{~g})$.

De l'ensemble des essais réalisés chez les salmonidés, les effets qualitatifs d'un traitement à la GH sur le transfert en mer sont de deux ordres

- réduction partielle ou totale des mortalités post-transfert ;

- réduction partielle ou totale du déséquilibre de la balance hydrominérale consécutif au transfert (figure 5).

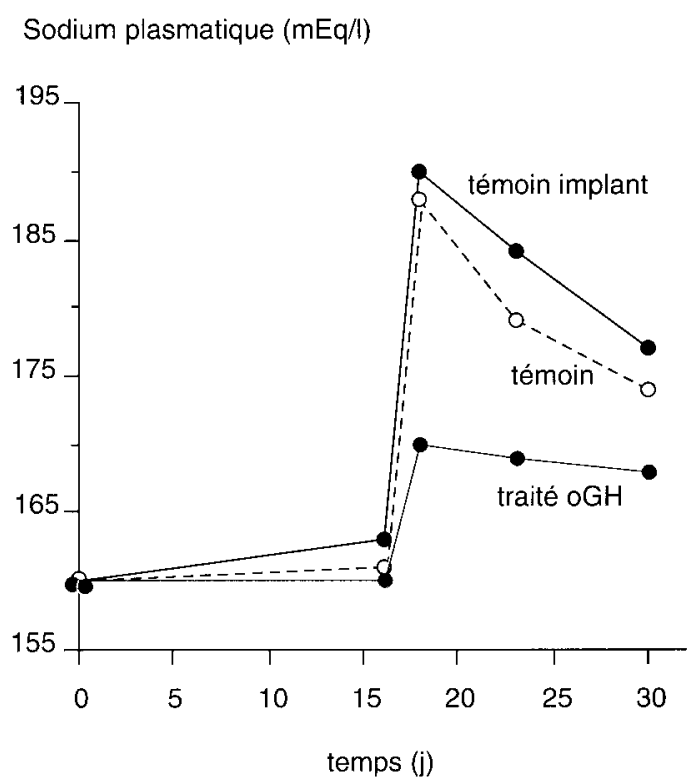

L'étude plus précise des périodes optimales de traitement a été réalisée chez le saumon atlantique : la meilleure réponse au traitement à la $\mathrm{GH}$ ovine est obtenue en octobre-novembre donc 6 mois avant la période normale de smoltification. En fin de période de smoltification, la GH par contre n'a aucun effet chez les smolts prêts à partir en mer (Boeuf et al 1990).

Dans toutes les expériences de traitement à la GH, il n'a jamais été observé de perte d'adaptabilité après que le passage en mer ait été réalisé avec succès. Les études faites sur la durée du traitement à appliquer ont montré que 3 à 4 injections à 3 jours d'intervalle ou la pose d'un implant cholestérol chargé en $\mathrm{GH}$ et relargant pendant 15 jours, suffisaient pour obtenir l'effet adaptation recherché. Les essais réalisés avec de l'hormone de croissance de truite obtenue par génie génétique ont permis d'obtenir des résultats qualitativement comparables à ceux obtenus avec de la $\mathrm{GH}$ ovine et cela à des doses 40 fois plus faibles (Boeuf et al 1991).

Des solutions alternatives au traitement à la $\mathrm{GH}$ existent. L'addition de sel dans l'aliment (jusqu'à $12 \%$ de $\mathrm{NaCl}$ ) induit une activation des mécanismes osmorégulateurs impliqués dans l'adaptation à l'eau de mer (Salman et Eddy 1987). Cette technique, qui s'est avérée efficace chez la truite arc-en-ciel, le saumon atlantique et la truite fario, mériterait d'être comparée, quant à son efficacité, avec un traitement à la GH. Par ailleurs, de nombreux travaux ont montré le rôle important que joue le cycle annuel de la photopériode dans le déclenchement de la smoltification chez le saumon atlantique. L'utilisation de programmes adéquats de photopériode permet d'accélérer la smoltification chez certaines espèces de saumon (Clarke et al 1985) ; ces protocoles doivent cependant être précisés pour chacune d'elles.

\section{6 / Modes d'administration de la GH}

Actuellement, 3 techniques compatibles avec les impératifs d'élevage intensif peuvent être envisagées : la pose d'implant, le traite-
Figure 5.

Effet d'un traitement par implant à la somatotropine ovine sur l'adaptation à leau de mer de la truite fario: 16 jours après la pose de limplant, les poissons sont transférés directement en eau de mer (35 g/l) puis les niveaux de sodium plasmatiques sont suivis pendant 14 jours (Almendras, Prunet et Boeuf, non publié) 


\section{Le traitement chronique à la rtGH permet d'augmenter la production des truiticultures sous réserve d'être associé à des techniques élaborées comme l'oxygénation de l'eau, le contrôle photopériodique de la date de ponte et la gestion informatisée des stocks de poissons.}

\section{Figure 6.}

Cinétique d'apparition de la somatotropine bovine dans le plasma sanguin après administration anale de l'hormone chez la truite arc-en-ciel ( $1 \mathrm{mg} / 500 \mu$ / $\mathrm{NaCl} 0,7 \%$ ) (d'après Le Bail et al 1989) ment par voie alimentaire avec supplémentation de l'aliment en $\mathrm{GH}$, la balnéation dans une solution enrichie en GH.

L'utilisation actuelle d'implant cholestérol, chargé en GH ovine permet d'obtenir des niveaux de GH élevés pendant 15 jours. Des essais d'implants injectables (microsphères) sont à l'étude. Compte tenu de la durée limitée de relargage des implants, cette technique semble plus compatible avec un objectif "stimulation de l'adaptation à l'eau de mer" et, en pratique, elle pourrait être associée à la vaccination anti-vibriose, classiquement administrée par injection à cette période précédant le transfert.

Différentes études réalisées chez la truite montrent que le transfert dans le plasma de protéines ingérées peut avoir lieu au niveau de l'intestin postérieur (revue de Mc Lean et Donaldson 1990). A partir de ces résultats, des expériences d'apport de GH directement au niveau de l'intestin ont été réalisées et ont montré la présence consécutive dans le plasma de GH intacte biologiquement active (figure 6). De plus, ce traitement, appliqué pendant plusieurs semaines, stimule la croissance des animaux traités (figure 7). Des recherches complémentaires restent cependant nécessaires avant qu'une technique fiable de traitement par addition de la $\mathrm{GH}$ dans l'aliment soit utilisable; il est indispensable en premier lieu de protéger la molécule pendant le transit stomacal. Cette mise au point est le préalable indispensable au développement des traitements chroniques destinés à accélérer la croissance.

Des essais de balnéation répétée dans une solution concentrée de GH pendant plusieurs semaines ont montré une augmentation significative de la croissance (Moriyama et Kawauchi 1990). Cette technique, réservée pour l'instant aux jeunes alevins, a été peu étudiée, elle nécessiterait d'être optimisée afin d'en améliorer l'efficacité ; cela passe par une connaissance plus précise des mécanismes et des lieux de pénétration de l'hormone.

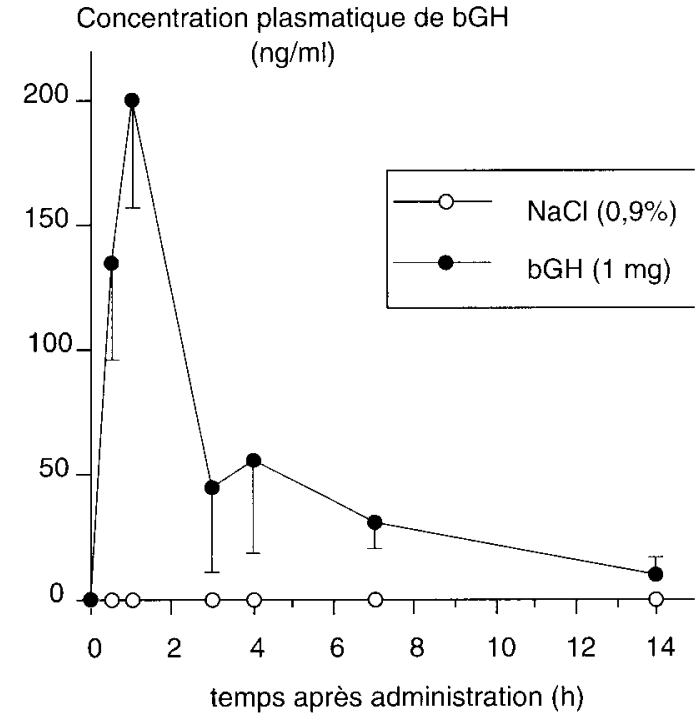

\section{2 / Effets sur la production salmonicole}

\section{1 / Simulation de l'impact d'un traitement chronique en truiticulture d'eau douce}

L'impact d'un traitement chronique à la rtGH sur le plan de production des truiticultures a été étudié à l'aide d'un logiciel de simulation du fonctionnement d'une pisciculture (logiciel "OPPEP", Fauré 1991) pour six types de conditions bioclimatiques (tableau 2) et trois spéculations (truite portion, truite à filet et grande truite). Cette typologie regroupe environ $90 \%$ des exploitations françaises.

Afin de permettre la comparaison des effets de la GH sur ces différents sites, leurs conditions de production ont été homogénéisées suivant les principes suivants :

- même débit moyen annuel : la moyenne des débits moyens mensuels est identique

- même volume d'exploitation $\left(3000 \mathrm{~m}^{3}\right)$

- souche de truite arc en ciel identique : performances de croissance identiques en fonction de la température.

Différentes stratégies d'élevage ont été retenues : soit l'exploitation utilise un cheptel de reproducteurs en conditions normales (une seule ponte annuelle), soit le contrôle photopériodique de la date de ponte est pratiqué (plusieurs pontes annuelles), soit l'éleveur importe des oeufs toute l'année. L'utilisation ou non de l'oxygénation des bassins a été testée. Enfin le traitement à la rtGH a été appliqué à partir d'un poids de 1 gramme jusqu'à 1 mois avant la vente.

Le modèle de croissance retenu est celui proposé par Muller-Feuga (1990) et l'effet $(\mathrm{KGH})$ du traitement à la rtGH en fonction de la température (T) a été modélisé à partir de l'ensemble des données bibliographiques:

$$
\mathrm{KGH}=-0,07433 \mathrm{~T}+2,525415
$$

Dans ces conditions, on note (tableau 3) qu'en règle générale l'utilisation de la $\mathrm{rtGH}$ a un effet négatif ou limité sur la production annuelle dans le cas d'un schéma élémentaire de production (pontes naturelles, sans oxygénation complémentaire). Ce n'est qu'après la mise en oeuvre d'équipements (oxygénation, photopériode) ou d'aménagement de gestion (importation d'oeufs) que l'on peut mettre en évidence un effet positif significatif. En ce qui concerne la production de truites à filets les effets positifs de la rtGH apparaissent dans la situation de base et bien entendu dans les situations techniques plus élaborées. Pour la production de grandes truites les effets sont moins importants bien que positifs là aussi.

Le traitement chronique à la rtGH permet une augmentation substantielle de la production des principaux types de truiticultures sous réserve d'être associé à des techniques qui permettent de s'affranchir des principaux facteurs limitants liés à la biologie de la reproduction de l'espèce et aux conditions bioclimatiques. La 
mise en oeuvre de cette technique nécessite des modifications structurelles importantes et accroît de manière conséquente le niveau de risque lié à un fonctionnement permanent à pleine capacité de stockage de l'élevage. De ce fait elle ne peut être guère utilisée que dans des exploitations à haut niveau technique incluant l'oxygénation de l'eau, le contrôle photopériodique de la date de ponte et la gestion informatisée des stocks de poissons.

Une projection au niveau global de la production française montre que l'impact potentiel $\mathrm{du}$ traitement à la $\mathrm{rtGH}$ serait d'ordre quantitatif, en accélérant brutalement l'augmentation de la production $(+60 \%$ ) ou/et d'ordre qualitatif en favorisant l'essor du filet, produit de substitution à la truite portion.

Par ailleurs, la pratique du traitement à la rtGH n'apparaît pas comme un facteur de régulation des variations de l'offre. Seules les techniques d'oxygénation et de contrôle de la date de ponte permettent un étalement de la production (figure 8). Cela renforce la nécessité qu'a l'éleveur d'associer ces techniques au traitement, surtout s'il souhaite approvisionner un atelier de filetage où la régularité est indispensable.

\section{2 / Simulation de l'impact d'un traitement unique pour la préparation des juvéniles de saumon au transfert en mer}

La simulation des effets d'un traitement unique par injection pour la préparation des juvéniles de saumon au transfert en mer a été réalisée en se référant aux conditions françaises ce qui minimise la portée de nos résultats puisque l'essentiel de la production se fait en Norvège et en Ecosse. Cependant, compte tenu de nos visites dans ces deux pays, nous pouvons estimer que les conclusions y seraient peu différentes. Notre étude montre (figure 9) que le transfert automnal de juvéniles traités n'augmente pas la production des exploitations s'il concerne l'ensemble des poissons mis en élevage, seule la période de vente est modifiée. Par contre, si l'éleveur transfêre une première bande d'animaux traités en automne et une seconde d'animaux naturellement smolts au printemps, la production augmente de $20 \%$ et surtout la période de vente est allongée. Le gain serait moindre dans des conditions plus septentrionales, où, comme en Norvège, les températures hivernales limiteraient considérablement la croissance. Dans ce cas seuls des transferts réalisés début octobre seraient intéressants pour profiter de deux mois de croissance avant l'hiver.

\section{3 / Impact économique potentiel d'un traitement chronique à la rtGH en truiticulture}

Dans un premier point la rentabilité est examinée par rapport aux pisciculteurs à par-
Figure 7. Effet sur la croissance de la GH de saumon administrée par voie anale à des juvéniles de truite arc-en-ciel. Les poissons reçoivent une administration hebdomadaire pendant 8 semaines (d'après Kawauchi et al 1992).

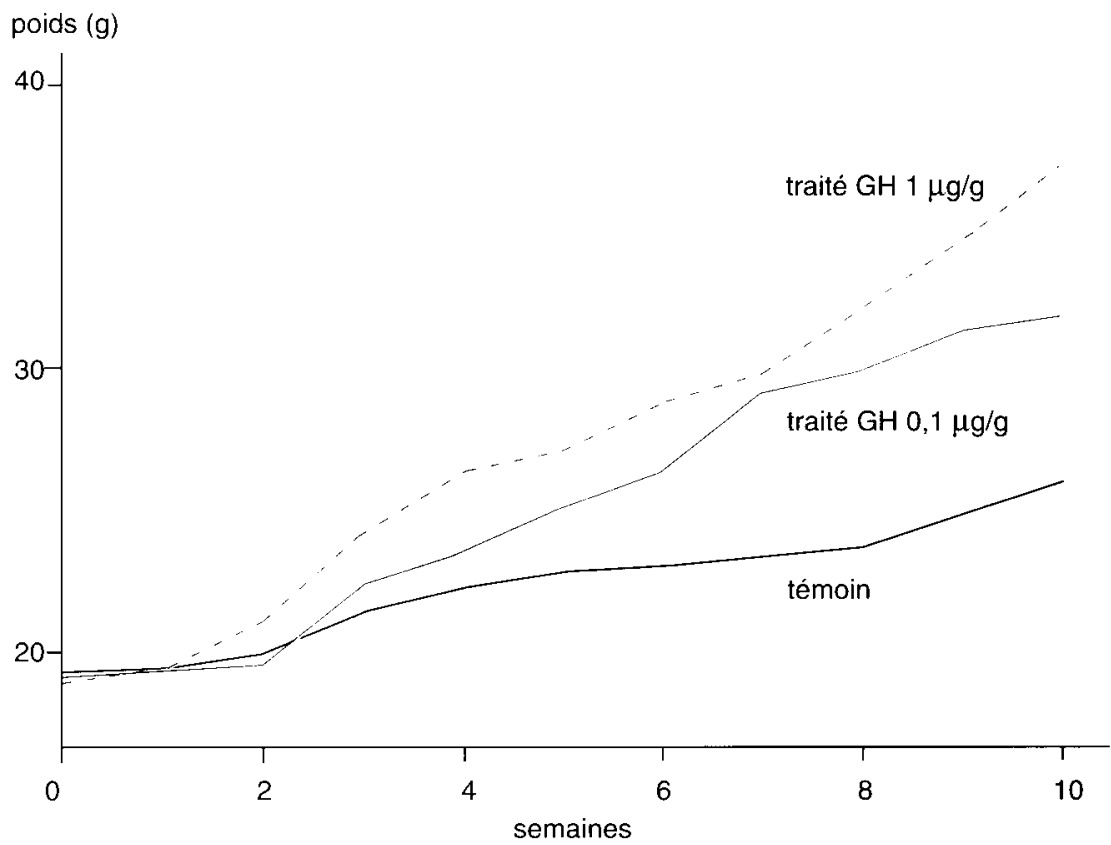

Tableau 2. Typologie des exploitations piscicoles étudiées.

\begin{tabular}{|c|c|c|c|}
\hline Type & $\begin{array}{l}\text { Conditions } \\
\text { thermiques }\end{array}$ & $\begin{array}{c}\text { Conditions } \\
\text { hydrauliques }\end{array}$ & Exemples \\
\hline 1 & $\begin{array}{c}\text { tempérées } \\
\text { amplitude moyenne }\end{array}$ & étiage marqué & Bretagne \\
\hline 2 & $\begin{array}{c}\text { tempérées } \\
\text { amplitude moyenne }\end{array}$ & amplitude faible & Normandie \\
\hline 3 & $\begin{array}{c}\text { tempérées } \\
\text { amplitude faible }\end{array}$ & amplitude faible & Landes \\
\hline 4 & $\begin{array}{l}\text { froides } \\
\text { amplitude forte }\end{array}$ & étiage marqué & Massif Central \\
\hline 5 & $\begin{array}{c}\text { froides } \\
\text { constantes }\end{array}$ & amplitude faible & Pyrénées \\
\hline 6 & $\begin{array}{l}\text { tempérées } \\
\text { constantes }\end{array}$ & amplitude faible & Sud-est \\
\hline
\end{tabular}

Tableau 3. Coefficient multiplicateur moyen de la production dû à l'utilisation de la $r \mathrm{tGH}$ en fonction de la situation technique antérieure.

$\begin{array}{lccc}\text { Niveau technique antérieur } & \text { Portion } & \text { Filet } & \text { Grosse } \\ \text { ponte naturelle sans oxygène } & 0,92 & 1.30 & 1,20 \\ \text { ponte naturelle avec oxygène } & 1,04 & 1,16 & 1,20 \\ \text { photopériode sans oxygène } & 1,40 & 1,54 & 1,36 \\ \text { photopériode avec oxygène } & 1,31 & 1,34 & 1,36 \\ \text { importation d'œufs sans oxygène } & 1,50 & 1,55 & 1,36 \\ \text { importation d'œufs avec oxygène } & 1,34 & 1,36 & 1,36\end{array}$


Figure 8. Variation de l'offre en truite portion dans une pisciculture de type breton en fonction des techniques en place et de l'utilisation ou non de la rtGH (simulation).

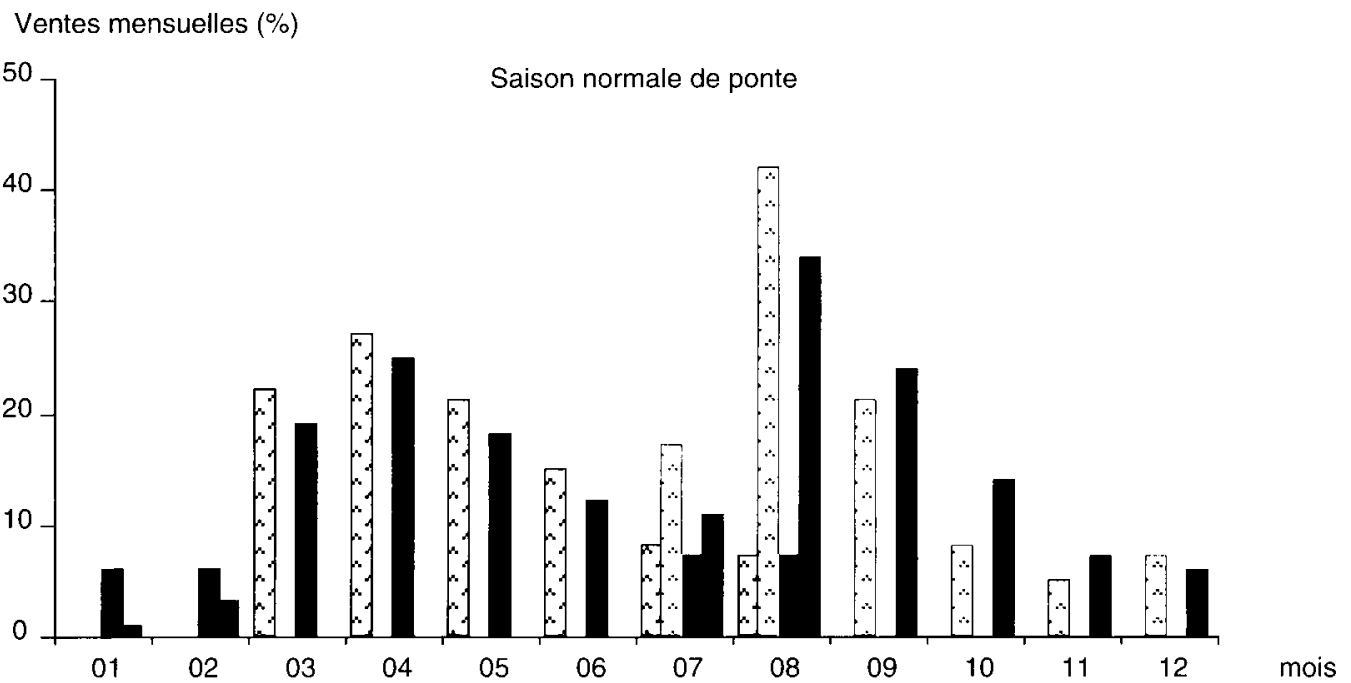

\footnotetext{
Le traitement à la rtGH ne permet pas de réguler les variations de l'offre. Seules les techniques d'oxygénation et de contrôle de la date de ponte permettent un étalement de la production.
}

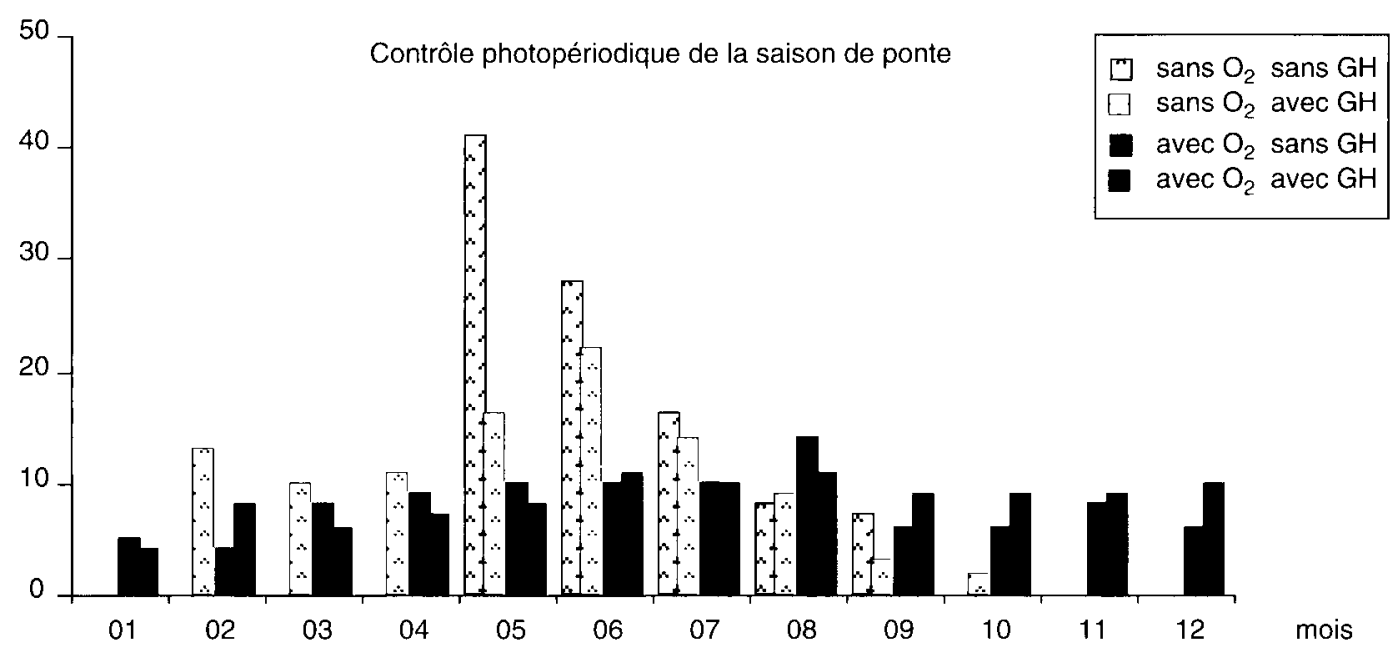

tir d'un certain nombre de simulations, compte tenu des effets de la rtGH. Le second point traite de la demande en s'attachant à mieux cerner l'attitude des consommateurs face aux produits susceptibles de provoquer des réactions de rejet. Enfin, le troisième volet récapitule, à partir d'un certain nombre de scénarios, comment se situerait le marché de la truiticulture en cas d'adoption de l'innovation et quelle serait la rentabilité sociale de la rtGH.

\section{1 / Rentabilité de la rtGH au niveau des entreprises}

Une telle étude se place dans le cadre théorique d'une concurrence pure et parfaite : l'entreprise, seule, n'a pas d'influence sur l'établissement du niveau de prix de vente.

En ce qui concerne les produits mis sur le marché, la forme traditionnelle est la truite dite "portion", de 200 à 250 g. Dans un souci de diversification, et grâce aux apports technologiques récents (triploïdisation), une part croissante des truites est aujourd'hui élevée jusqu'à $700 \mathrm{~g}-1 \mathrm{~kg}$ pour le filetage, et $1,5-3 \mathrm{~kg}$ pour le fumage. On a donc une multitude de formes, depuis la truite vendue vivante pour les étangs de pêche de loisir, jusqu'aux plats cuisinés prêts à l'emploi.

La répartition géographique de la production dépend essentiellement de facteurs climatiques, les températures moyennes et leurs variations saisonnières et les débits d'eau. Les Landes produisent actuellement une quantité importante de truite de $1 \mathrm{~kg}$ pour le filetage et de 2 à $3 \mathrm{~kg}$ pour le fumage. La Bretagne, traditionnellement productrice de truite portion, s'oriente progressivement vers des tailles de truites à fileter de $700 \mathrm{~g}$ et produit peu de grosses. Les zones de montagne semblent plutôt essayer de diversifier les services à la vente (étangs de pêche), les espèces produites (espèces d'eau froide comme la fario, les ombles, etc) ou se concentrer sur l'activité d'écloserie. Les entreprises de transformation se trouvent donc principalement dans les Landes et en Bretagne. C'est dans ces trois grandes régions, Bretagne, Landes, Massif Central que l'on a cherché à évaluer la rentabilité de cette innovation. 
Figure 9. Variation de l'offre en saumon atlantique en fonction du transfert au printemps ou à l'automne de juvéniles naturellement préadaptés ou traités avec de la rtGH. Le graphique du bas concerne le cas où l'éleveur transfère sur le même site d'élevage les deux types de juvéniles (simulation).

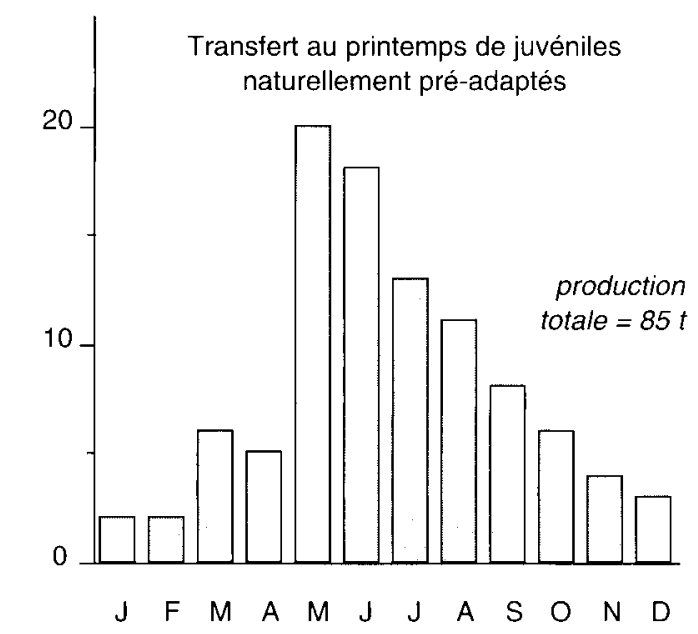

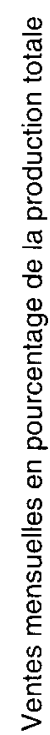

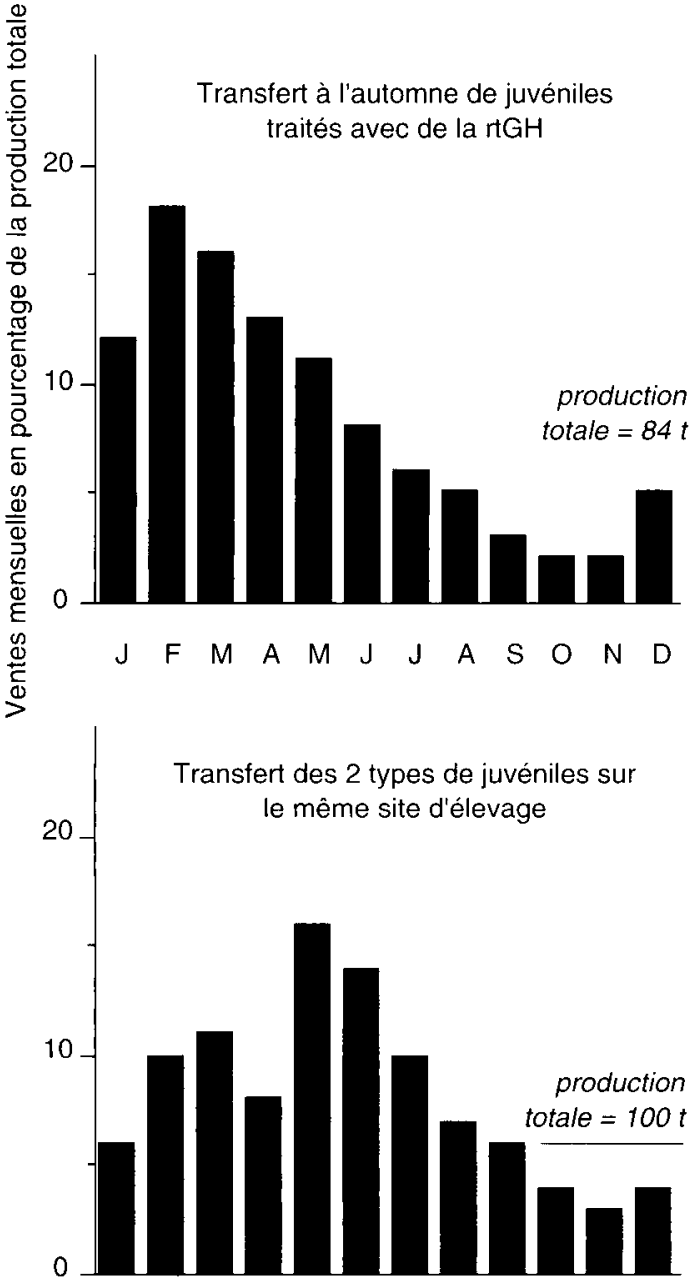

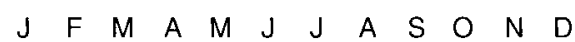

L'exploitation type a un volume de production de $3000 \mathrm{~m}^{3}$, effectue des alevinages naturels en Bretagne et dans le Massif Central, complété par des alevinages issus de photopériode dans les Landes, et utilise l'oxygénation artificielle de l'eau. Trois types d'activités sont tour à tour effectuées sur cette exploitation : la truite portion de $200 \mathrm{~g}$, la truite à filet de $700 \mathrm{~g}$ et la grosse truite de $2 \mathrm{~kg}$.

Une analyse comparée des structures de coût montre que les différences d'un produit à l'autre et d'une région à l'autre sont imputables aux postes frais financiers et amortissements. Les premiers sont dus pour l'essentiel aux frais d'immobilisation du stock. Ils dépendent donc de la longueur du cycle de production, et sont d'autant plus importants que les températures du site sont basses et éloignées de l'optimum de croissance. Les frais d'amortissement par $\mathrm{kg}$ sont, eux, inversement proportionnels à la production de l'exploitation et sont aussi dépendants de la longueur du cycle de croissance.

Dans un premier temps les effets de la rtGH peuvent être analysés dans le cadre d'entreprises fonctionnant à un niveau de production inchangé. Pour prix de l'hormone, on a retenu le supplément de prix de l'aliment complété en caroténoïdes, servant à l'obtention de truites "saumonées", soit $0,75 \mathrm{~F} / \mathrm{Kg}$ de truite.

Le principal enseignement de cette simulation est que les gains sont d'autant plus importants que les conditions de croissance sont défavorables. Les gains les plus importants se font sur le poste frais financiers et sur l'aliment. Dans les Landes et le Massif Central ces gains sont respectivement de $0,60 \mathrm{~F}$ et $0,80 \mathrm{~F}$ sur la portion, $0,70 \mathrm{~F}$ et $1,10 \mathrm{~F}$ sur la truite à filet et $1,10 \mathrm{~F}$ et $2,30 \mathrm{~F}$ sur la grosse truite. Malgré cela, les coûts de production de la truite sont plus intéressants dans les Landes, avec un avantage de 5 à $10 \%$ par rapport à la Bretagne et de 10 à $15 \%$ par rapport au Massif Central.

Dans un deuxième temps les effets de la rtGH sont étudiés dans l'hypothèse d'un effet maximum en matière d'augmentation de la production, situation où les pisciculteurs maîtriseraient et utiliseraient toutes les techniques nécessaires de décalage des pontes au cours de l'année. Cela amène à une situation assez difficile à gérer, la capacité de stockage de l'exploitation étant utilisée à plein pendant presque toute l'année.

Dans ce cas, les résultats de production dans les trois régions et pour les trois produits sélectionnés, font apparaître un doublement de la production de truite portion en Bretagne et dans le Massif Central. La production de truite de moins de $700 \mathrm{~g}$ augmente fortement en Bretagne. Dans tous les autres cas de figure l'accroissement varie autour de $50 \%$ à plus ou moins $10 \%$ près.

En ce qui concerne les coûts de production, il faut tenir compte du surcroît de travail engendré par le supplément de production. Cela se traduit par une augmentation des charges en travail d'environ $50 \%$ mais il y a en contrepartie une diminution des charges d'amortissement. Ainsi, la truite portion
Les cô̂ts de production sont d'autant plus importants que le cycle de croissance est long.

L'utilisation de la GH permet donc une diminution des coûts plus importante dans les régions d'eau plus froide. 
devient aussi rentable à produire en Bretagne que dans les Landes. Au total, les gains s'établissent de $0,50 \mathrm{~F}$ pour la portion dans les Landes à 2,50 $\mathrm{F}$ pour la grosse truite dans le Massif Central. Malgré cela, la hiérarchie des coûts par rapport à la production sans hormone est inchangée.

Dans une situation où l'on maintient les mêmes productions sur l'exploitation, les calculs montrent que l'emploi de la rtGH permettrait aux pisciculteurs de supporter une baisse des prix des produits de 10 à $25 \%$, et ceci, particulièrement en Bretagne. Toutefois, les calculs ne prennent pas en compte une éventuelle hausse du coût du travail imputable à l'accroissement de production.

La figure 10 résume l'évolution des marges d'exploitation pour la truite portion et le filet en fonction d'une utilisation éventuelle de l'hormone, et d'une variation des prix de vente, et cela en Bretagne et dans les Landes. On y observe des gains supérieurs en Bretagne et qui réduisent la différence de coût de production entre ces deux régions, notamment pour ce qui concerne la portion. En outre, on a mis en évidence la variation de prix maximale dans chaque région qui autorise une variation de marge positive.

A ce stade de l'étude on peut dire que, malgré les gains supérieurs que la rtGH permettrait dans les régions d'eau plus froide, il persisterait des différences de coûts de production entre les régions, surtout pour la truite à filet et la grosse truite. D'autre part, la rentabilité de la production de portion semble ici renforcée, et au regard uniquement de la phase de production, il ne semble pas qu'une diversification vers la truite à filet ou la grosse truite améliore la rentabilité des piscicultures.

\section{2 / L'attitude des consommateurs et des producteurs}

Malgré une artificialisation croissante des systèmes de production, la perception des salmonidés par le public est très favorable. Deux enquêtes récentes sur les attitudes et les comportements des français et plus largement des européens à l'égard de la truite (Gabriel 1990, Suquet 1991) font ressortir l'idée de nature préservée, ainsi qu'une notion de produit sain et naturel. Ce dernier aspect l'emporte, d'ailleurs, sur les qualités diététiques. Concernant le saumon, ces symboles sont plus accusés et les éleveurs écossais vantent le saumon atlantique "roi des poissons", "l'une des espèces les plus recherchées et les plus admirées". Leur présentation des produits de la salmoniculture met l'accent sur la similarité des modalités de la croissance des saumons d'élevage et des saumons sauvages indiquant même que c'est grâce au développement de l'élevage que l'on a pu préserver l'espèce dans les rivières écossaises. Toute la stratégie de marketing repose sur le caractère naturel de ce poisson et ses qualités diététiques. Très clairement on laisse entendre au consommateur qu'il achète un produit de luxe, assez mystérieux (les migrations) et, plus que naturel, sauvage.
Figure 10. Evolution des marges au kilogramme de truite (portion ou à filet) en fonction d'une baisse des prix (simulation).

Marge en F/kg

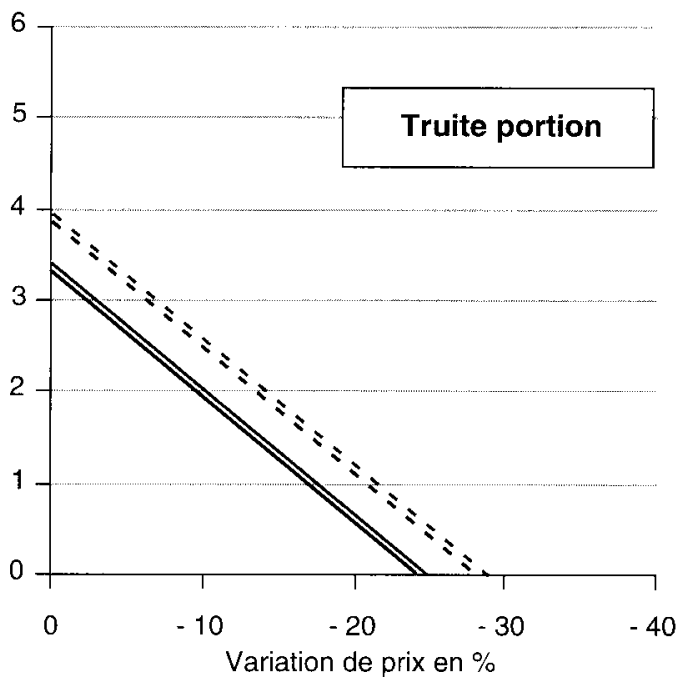

Marge en $\mathrm{F} / \mathrm{kg}$

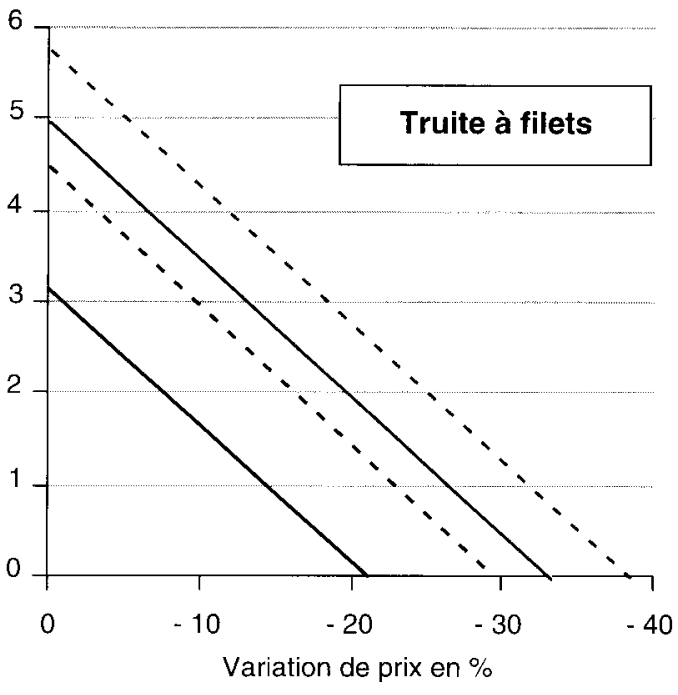

\begin{tabular}{|lll|}
\hline $\begin{array}{l}\text { Bretagne } \\
\text { Landes }\end{array}$ & sans GH & avec GH \\
& & $\ldots . .$. \\
\hline
\end{tabular}

Les éleveurs européens défendent avec force cette image naturelle ce qui les amène à prendre position non seulement contre l'utilisation de l'hormone de croissance mais aussi contre les recherches la concernant (Fish farming International, 1991, vol. 18, $n^{\circ} 7$ ). L'affaire du veau aux hormones en France montre bien que des accusations très graves sur la qualité de la viande et ses effets nocifs ont un effet immédiat important. Mais, à plus long terme, les révélations et la campagne de boycott ne modifient pas les tendances de fond : Combris (1990) a montré que la rupture de la demande était antérieure et reposait sur des facteurs techniques et économiques : facteurs techniques avec le développement de 
l'élevage en batterie et ses effets sur la qualité, facteurs économiques avec l'apparition d'un substitut (viande de dinde) moins cher.

Dans ces conditions, on comprend l'opposition des responsables professionnels à l'utilisation de la rtGH. Leur crainte est que la $\mathrm{GH}$, assimilée aux additifs alimentaires, ou pire aux oestrogènes de synthèse, ne dégrade le caractère "naturel" du produit et entraîne un rejet. Il est certain que l'appellation de peptide au lieu d'hormone banaliserait le produit et le rendrait plus inoffensif aux yeux du public.

Cette opposition va de pair avec l'idée que, dans l'hypothèse d'une autorisation d'utilisation de la BST dans les élevages laitiers, il deviendrait impossible de bloquer la rtGH. Les producteurs écossais de saumons envisagent alors d'utiliser l'argument a contrario en élargissant leur politique de label (Le marin, $n^{\circ} 2348$ du 10-07-92), qui garantit la fourniture de "produit naturel non traité".

Cette attitude ainsi que l'exemple de l'aviculture permettent de discerner ce qui pourrait se passer : une segmentation du marché avec des salmonidés de consommation courante et, à côté, des produits de haut de gamme. Ces derniers correspondraient à une labélisation avec un cahier des charges prévoyant la nature de l'alimentation et la durée d'élevage. Pour des raisons sociales, il conviendrait que cette production sous label bénéficie aux trutticulteurs les plus défavorisés, ceux de montagne. Mais on peut craindre que n'étant pas les mieux organisés, ils ne soient pas à même d'en profiter.

\section{3 / Evaluation du bénéfice social}

$\mathrm{Si}$, comme on l'a vu précédemment, l'utilisation de la rtGH est rentable au niveau des pisciculteurs, il convient aussi d'estimer son intérêt pour la collectivité (producteurs et consommateurs), et de calculer le bénéfice social. Il faut donc tenir compte des conséquences des variations de l'offre sur l'équilibre de marché tant du côté des producteurs (modification de profit) que des consommateurs (changement du surplus à partir des modifications des prix payés).

Cet équilibre dépend du taux d'adoption par les pisciculteurs de la rtGH, si elle est autorisée, et du degré d'acceptation du produit par les consommateurs. En fonction de ces paramètres on peut envisager diverses éventualités en voyant à chaque fois le bénéfice social. Cela a conduit à l'élaboration d'un certain nombre de scénarios.

Le calcul des variations des prix et de quantités repose sur des approximations du premier ordre. Pour calculer les variations de surplus on suppose que l'offre et la demande sont linéaires, donc à élasticités variables en fonction du prix, ce qui est moins contraignant qu'un raisonnement à élasticités constantes. Quant au déplacement de la courbe d'offre on a admis qu'il était vertical, ce qui permet une estimation sans biais de la variation du surplus social.
L'équilibre 1990 du marché sert de point de référence pour les calculs. Il correspond à :

$$
\text { Offre : Qo }=36000 \mathrm{t} \text {; Prix : Po }=15 \mathrm{~F} / \mathrm{kg}
$$

Les truites portions représentent environ $30000 t$, le reste de la production se répartit en quantités à peu près égales entre la truite à fileter de $400-800 \mathrm{~g}$ et la grosse truite de 1 500-2 000 g. Le prix retenu est une moyenne pondérée : $14 \mathrm{~F}$ à $14,50 \mathrm{~F}$ pour la portion, avec un supplément de près de $1 \mathrm{~F}$ pour les truites roses et de $5 \mathrm{~F}$ environ pour certaines truites de montagne ; $16 \mathrm{~F}$ à $16,50 \mathrm{~F} / \mathrm{kg}$ pour les truites moyennes; $18 \mathrm{~F}$ à $20 \mathrm{~F}$ pour les grosses truites.

En ce qui concerne l'offre il faut distinguer le long terme du court terme. Dans le court terme les adaptations ne portent que sur les facteurs de production variables, d'où une variation de l'offre aux variations de prix limitée (élasticité-prix de 1,1). Dans le long terme les possibilités d'adaptation sont plus importantes puisque des investissements sont envisageables ce qui permet une réaction de plus grande ampleur aux changements de prix (l'élasticité-prix retenue vaut ici 2,5).

Quant au déplacement de l'offre, on a retenu une augmentation de $9 \%$ à court terme et de $20 \%$ à long terme. ces pourcentages tiennent compte des résultats des simulations de baisse de coût dans les piscicultures adoptant la rtGH, et de la diffusion prévisible de cette innovation parmi les producteurs. le taux de diffusion plus important à long terme qu'à court terme explique la différence dans le pourcentage de déplacement de l'offre.

Pour la réponse de la demande aux variations de prix, on s'est basé sur les analyses de la consommation alimentaire faites en France. Pour une diminution des prix de $10 \%$ on a supposé que la demande augmentait de $8 \%$ à court terme, et de $12 \%$ à long terme. De plus, à long terme s'il y a modification des préférences des consommateurs en faveur de produits peu élaborés une augmentation de $18 \%$ est envisageable.

Toutefois l'introduction de la rtGH peut entraîner des réactions plus ou moins négatives de la part des consommateurs. On a donc examiné plusieurs hypothèses de diminution de la demande : baisse limitée - $5 \%$ et - $10 \%$; forte baisse - $40 \%$ et effondrement - $80 \%$. Des hypothèses d'augmentation de la demande ont été aussi étudiées : $+5 \%$ et $+10 \%$.

Avant de résumer les résultats (cf. figure 11) il convient de mettre en garde contre toute vision mécaniste qui conduirait à des conclusions erronées. Pour le comprendre prenons deux cas extrêmes sur la diffusion de la rtGH et la réaction des consommateurs. Au plan de la pisciculture, l'utilisation de la rtGH peut augmenter très largement la production, ce qui implique un accroissement potentiel toutes choses égales par ailleurs de la production nationale de l'ordre de $50 \%$. Mais la clause, toutes choses égales par ailleurs, n'est pas vérifiée du fait de l'interaction offre-demande. Les quantités effectivement produites vont être

\author{
Pour le \\ consommateur, les \\ salmonidés ont une \\ image de produit \\ sain et naturel, les \\ responsables \\ professionnels sont \\ donc tout à fait \\ opposés à \\ l'utilisation de la \\ rtGH. Le marché \\ serait alors \\ segmenté, avec d'un \\ côté les salmonidés \\ de consommation \\ courante et, de \\ l'autre, des produits \\ de haut de gamme.
}


L'intérêt collectif d'utiliser la rtGH a été testé selon différents scénarios faisant intervenir les variations de la production et les réactions des consommateurs.

Dans tous les cas, les problèmes

d'ajustement offredemande nécessitent une réorganisation de la profession. très inférieures et on aura en fin de compte un accroissement de la production inférieur à $20 \%$. De façon symétrique un écroulement de la demande va être en partie amorti du fait d'un ajustement des prix à la baisse.

Les scénarios de diffusion progressive de la rtGH se traduisent à demande constante par une baisse sensible des prix à court terme (4$5 \%$ ) plus importante à long terme (14-15\%) presque compensée par l'augmentation de la production ( $4-5 \%$ à court terme, $12-16 \%$ à long terme), d'où une recette stable ou en légère baisse dans le long terme. Toutefois le gain sur les coûts de production permet aux producteurs d'améliorer leur situation avec une augmentation du surplus (égal ici à la marge nette) compris entre 26 et 38 millions de $\mathrm{F}$ par an soit 5 à $7 \%$ de la recette totale, selon les hypothèses. L'innovation bénéficie aux consommateurs et donc doit être considérée comme socialement intéressante.
Ces résultats sont sensibles aux réactions des consommateurs. Toutefois, cela ne remet pas en cause l'intérêt collectif de la rtGH. Les variations de surplus restent positives, mais beaucoup plus faibles. Le gain pour les producteurs n'est plus que de 7 à 14 millions de $\mathrm{F}$ par an à court terme par exemple.

Si maintenant la diffusion de la rtGH s'accompagne d'une diminution sensible et durable de la demande, son intérêt à court terme disparaît. En effet la diffusion n'est pas suffisante pour permettre une baisse des coûts qui compense le recul de la demande. On peut alors s'attendre à court terme à une baisse des prix de l'ordre de $10 \%$, des quantités produites de l'ordre de $2 \%$ et des recettes. Dans ce cas le bilan pour les producteurs et les consommateurs est proche de zéro sinon négatif, et on peut considérer que la rtGH n'est pas collectivement intéressante. Le sens des résultats s'inverse à long terme dès lors que l'adoption de l'innova-

Figure 11. Evaluation du bénéfice social de l'éventuelle utilisation de la rtGH en salmoniculture, selon différents scénarios.

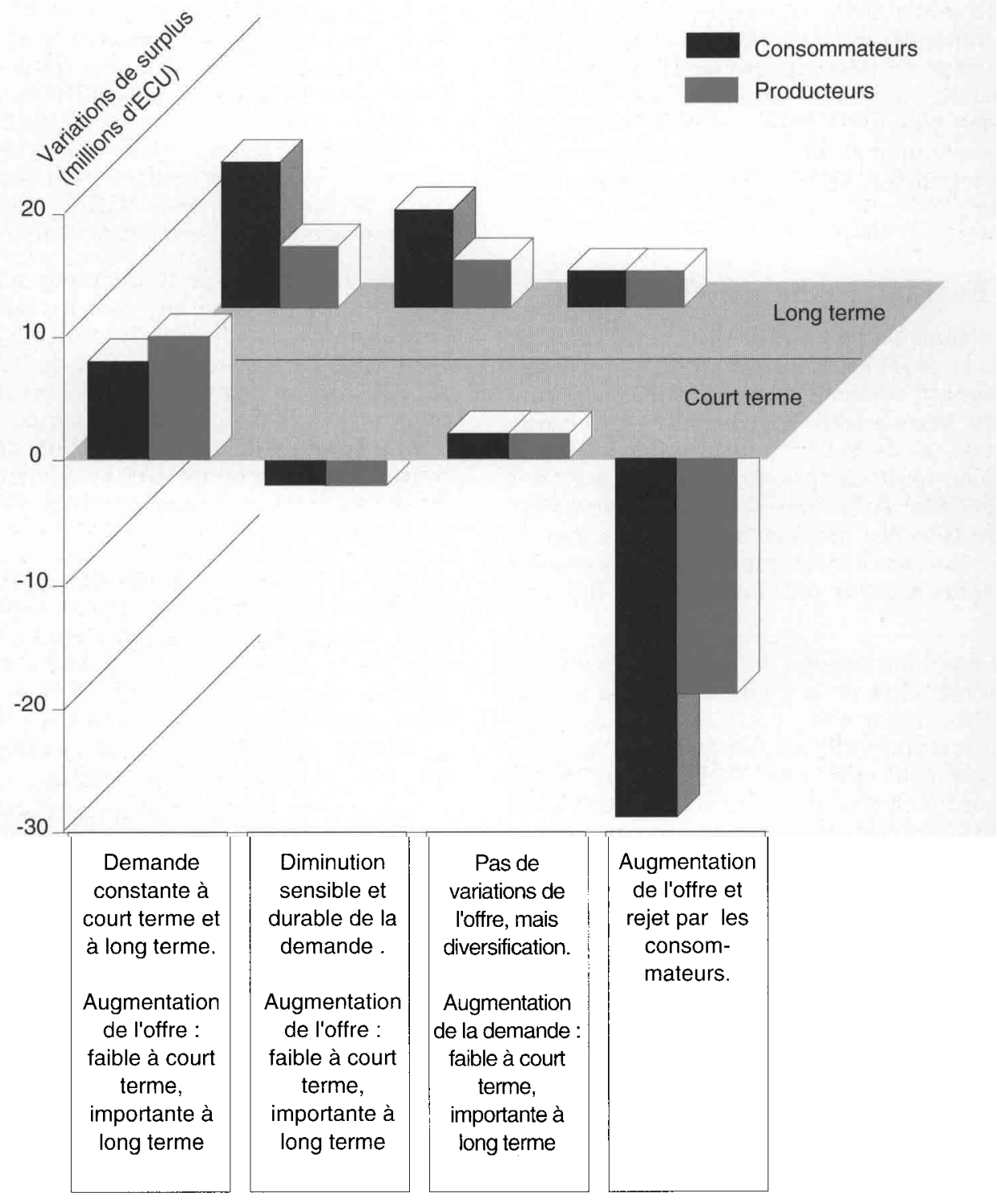


tion permet une baisse des coûts telle qu'il y a diminution des prix (15 à $17 \%$ ), augmentation des quantités ( 8 à $13 \%$ ) baisse de la recette (4 à $10 \%)$, mais augmentation du surplus des producteurs (19 à 30 millions par an) et de celui des consommateurs.

Le scénario que l'on peut qualifier d'optimiste, est fondé sur une diversification de la production vers des produits plus élaborés accompagnée d'une amélioration de l'image de marque et une augmentation durable de la demande. Sa mise en oeuvre permettrait une légère augmentation des prix ( $2 \%)$, des quantités produites $(2$ puis $6 \%$ ) et de la recette ( 5 puis $8 \%$ ). On aurait alors une amélioration sensible de la situation des producteurs et des consommateurs. Toutefois la diversification entraîne une hausse relative des coûts de production, qui compense partiellement les gains dus à la rtGH. Il en résulte une augmentation du surplus de production assez limitée : 12-13 millions de $\mathrm{F}$ par an soit seulement $2 \%$ de la recette totale.

Les scénarios décrivant des situations de court terme sont basés sur une hypothèse de rejet de la rtGH par les consommateurs. Dans ce cas la baisse de la demande annule et au-delà les effets positifs en termes de coût de production de l'innovation. Une baisse de prix de 22 à $47 \%$ et des quantités de 14 à $42 \%$ est alors possible. On retrouve là le scénario vécu après le boycott du veau par les consommateurs. Il entraîne une diminution considérable de la recette de $33 \%$ à $70 \%$ selon les paramètres retenus avec en corollaire une chute de la marge nette réalisée par les producteurs et du bienêtre des consommateurs.

Si on peut penser qu'à long terme l'adoption de la rtGH se traduirait par des bénéfices collectifs partagés par les producteurs et les consommateurs, la phase transitoire est délicate. La voie est très étroite entre la réussite et le rejet. Ce dernier entraînerait une restructuration complète de la branche. La stratégie de la réussite semble bien passer par la diversification et l'amélioration de l'image de marque. Même dans ce cas on peut s'attendre à des effets sur la structure de la branche, certains producteurs bénéficiant plus que d'autres du surplus.

\section{Conclusion}

Le développement des recherches en biotechnologies est une réalité, bénéficiant de financements importants aux niveaux des Régions, des Nations et de la Communauté Européenne. Cette diversité des financements montre combien les sociétés, par l'intermédiaire de leurs élus, mettent d'espoirs dans les biotechnologies. L'intérêt potentiel des biotechnologies en agriculture fera que le développement des recherches dans ce domaine ira croissant. $\mathrm{Au}$ cours de notre enquête auprès des professionnels de la salmoniculture, il n'est pas apparu de véritable refus des biotechnologies. Les préoccupations des éleveurs sont de trois ordres: le développement du marché, la prophylaxie sanitaire et le souci de se mettre en conformité avec la législation relative aux rejets. Lorsque les biotechnologies sont jugées potentiellement intéressantes dans la lutte contre les maladies, il y a une assez forte adhésion à ces innovations.

La conduite des professionnels est dictée en priorité par la crainte des réactions des consommateurs pouvant mettre gravement en cause l'équilibre du marché. Cette attitude, reposant sur une analyse de court terme, est parfaitement compréhensible. Il faut cependant prendre en compte la diversité des élevages. Le niveau technique est extrêmement varié, allant de la petite exploitation familiale alimentant un marché local, à la grande exploitation industrielle fournissant les réseaux de grande distribution. Il est clair que le développement des biotechnologies favoriserait les secondes au détriment des premières. Mais cela ne se passe-t-il pas de la même manière avec les perfectionnements de la zootechnie traditionnelle? Actuellement, le seul point commun entre une pisciculture industrielle et une pisciculture familiale de montagne, par exemple, est la truite ! Tout le reste differe, le niveau technique du personnel, le matériel, la gestion, la commercialisation ... En l'absence de réflexion sur les possibilités de mettre en place un label de qualité qui profiterait aux petites unités de montagne, c'est à une forte concentration que nous assisterons. Les entreprises moyennes, alimentant le même marché que les piscicultures industrielles seront alors probablement les premières touchées.

Les problèmes de l'acceptation, nous l'avons vu plus haut, reposent en particulier sur la notion de besoin. La question du besoin dépasse le domaine des biotechnologies, mais comment les biotechnologies pourraient-elles échapper à cette question? Si l'on se limite à la salmoniculture, activité piscicole typique des pays du nord qui, avec le Japon, l'Europe, le Canada et les USA, produisent l'essentiel, la notion de besoin a plusieurs composantes.

A-t-on besoin de produire autant sinon plus de poissons ? La réponse semble affirmative si l'on considère l'augmentation de la consommation individuelle de truite pendant la dernière décennie (Gabriel 1990). Cependant l'exemple du saumon Norvégien est là pour rappeler que la croissance doit suivre le marché et non le précéder. L'augmentation de production doit être raisonnée (voir l'attitude de la Fédération Européenne de Salmoniculture qui prévoit $3 \%$ par an) et non exponentielle comme elle le fut en Norvège. De ce point de vue une trop grande disponibilité en rtGH pourrait déstabiliser le marché par une augmentation brutale de l'offre, si l'hypothèse d'une diversification des produits (filets portions) ne devient pas réalité.

A-t-on besoin de mieux utiliser les matières premières ? La disponibilité en matières premières de qualité est vitale pour les élevages industriels. Dans le cas de la salmoniculture, il faut rappeler que $35 \%$ à $50 \%$ de l'aliment est composé de farine de poisson et que la principale source lipidique provient aussi du poisson. Cela signifie que la production européenne (Norvège comprise) consomme plus de 1 million de tonnes de poissons frais provenant de la pêche, en compétition avec d'autres élevages et 
avec la transformation directe de ce poisson, comme c'est le cas avec le surimi. Dans ce contexte, aggravé par la stagnation des captures, toute technique permettant une consommation moindre de protéines est la bienvenue ; la supplémentation en rtGH par son effet positif sur l'épargne protéique, apparaît bien comme une technique intéressante, correspondant à un besoin réel.

Un autre besoin concerne la protection de l'environnement. Peut-on produire autant, tout en diminuant les rejets? Aujourd'hui c'est un des problèmes les plus graves auxquels sont confrontés les pisciculteurs. Des aliments sont apparus sur le marché, plus riches en lipides, pour diminuer la pollution azotée. Tout ce qui augmente le coefficient de transformation de l'aliment va dans le sens d'une diminution des rejets polluants. Là encore, les traitements à la rtGH peuvent être utiles par leurs effets bénéfiques sur l'indice de consommation (quantité d'aliment ingéré /gain de poids) qui peut diminuer de $20 \%$.

En résumé, la rtGH présente des potentialités non négligeables (meilleure utilisation des matières premières, diminution de la pollution) pour la salmoniculture, tout autant que des risques (mauvaise image du produit, risque de surproduction, impact sur la structure de la profession). Dans la mesure où son innocuité serait prouvée, sa mise en oeuvre devrait être progressive, concertée avec les producteurs, et s'accompagner de mesures en faveur de la qualité (label).

\section{Références bibliographiques}

Boeuf G., Le Bail P.-Y., Prunet P., Smal J. 1991. Stimulation of the smoltification by hormonal treatment in the atlantic salmon. 5th International Symposium on Fish Physiology. Odense University, august 14-17, 1991. Abstract.

Boeuf G., Prunet P., Le Bail P.-Y., 1990. Un traitement à l'hormone de croissance peut-il stimuler la smoltification du saumon atlantique? C. R. Acad. Sci., 310, 75-80

Chevassus B., Quillet E., Chourrout D., 1984. La production de truites stériles par voie génétique. Pisc. Fr., 78, 10-19

Chourrout D., 1984. Pressure-induced retention of second polar body and suppression of first cleavage in rainbow trout : production of all-triploids, alltetraploids, heterozygous and homozygous diploid gynogenetics. Aquaculture, 36, 111-126.

Chourrout D., Guyomard R., Houdebine L.M., 1986. High efficiency gene transfer in rainbow trout (Salmo gairdneri Rich.) by microinjection into egg cytoplasm. Aquaculture, 51, 143-150.

Clarke W.C., Lundqvist H., Eriksson L.-O., 1985 , Accelerated photoperiod advances seasonal cycle of seawater adaptation in juvenile Baltic salmon, Salmo salar L.. J. Fish Biol., 26, 29-35.

Combris P., 1990. Changements structurels: le cas des consommations alimentaires en France de 1949 à 1988. 7è journées de Microéconomie Appliquée, Montréal, mai 1990.

Cordonnier P., 1989. Impact économique de l'utilisation de la somatotropine dans les systèmes laitiers français. INRA Prod. Anim., 2, 313-316.

Cravedi J.P., Perdu-Durand E., Prunet P., Fauconneau B., 1991. Effects of growth hormone treatment on cytochrome P-450 and xenobiotic metabolizing enzymes of rainbow trout. International Congress on Research for aquaculture: fundamental and applied aspects. Antibes - Juan les pins, october 6-10, 1991. Abstract.
Dorson M., Chevassus B., 1984. Etude de la réceptivité d'hybrides triploïdes truite arc-en-ciel X saumon coho à la nécrose pancréatique infectieuse et à la septicémie hémorragique virale. Bull. Fr. Pêche Piscic., 296, 29-34.

Fauconneau B., Le Bail P.-Y., Mady M.P., 1988. Effets de différents facteurs de croissance sur la composition corporelle chez les salmonidés. C.R. 10ème Réunion SIFA: Bases Biologiques de l'Aquaculture, Saint Pée sur Nivelle. Octobre 1988.

Folmar L.C., Dickhoff W.W., 1980. The parr-smolt transformation (smoltification) and seawater adaptation in salmonids. Aquaculture, 21, 1-37.

Gabriel R., 1990. Une étude de marché de la truite portion en Europe. Pisc. Fr., 102, 5-100.

Gaignon J.L., 1987. L'élevage des juvéniles de saumon atlantique (Salmo salar). Pisc. Fr., 90, 5-56.

Gilmore R.D., Engelking H.M., Manning D.S., LeonG J.C., 1988. Expression in Escherichia coli of an epitope of the glycoprotein of Infectious Hematopoietic Necrosis virus protects against viral challenge. Biotechnology, 6, 295-300.

Haffray P., Guinebert E., Stevens P., 1990. Problématique de l'amélioration génétique des poissons d'eau douce en France. Rapport SYSAAF, $61 \mathrm{p}$.

Houdebine L.M., 1991. Les biotechnologies animales. INRA Prod. Anim., 4, 81-88.

Le Bail P.-Y., Sire M.F., Vernier J.F. 1989. Intestinal transfer of growth hormone into the circulatory system of the rainbow trout, Salmo gairdneri: interference by granule cells. J. Exp. Zool., 251, 101-107.

Le Bail, P.-Y., Perez-Sanchez J., Yao K., Maisse G., 1992. Effect of GH treatment on salmonid growth: study of the variability of response; Comp. Biochem. Physiol, sous presse.

Manning D.S., LeonG J.C., 1990. Expression in Escherichia coli of the large genomic segment of Infectious Pancreatic Necrosis virus. Virology, 179, 16-25. 
McLean E., Donaldson E.M., 1990. Absorption of bioactive proteins by the gastrointestinal tract of fish: a review. J. Aqua. Anim. Health, 2, 1-11.

Moriyama S., Kawauchi H., 1990. Growth stimulation of juvenile salmonids by immersion in recombinant salmon growth hormone. Nippon Suisan Gakkaishi, 56, 31-34.

Muller-Feuga A., 1990. Modélisation de la croissance des poissons en élevage. Rapport scientifique et technique IFREMER N²1.
Quillet E., Krieg F., Happe A., Chevassus B., 1986. Etude des possibilité de transfert automnal en mer de juvéniles de truite fario (Salmo trutta). Bull. Fr. Pêche Piscic., 303, 125-133.

Salman N.A., Eddy F.B., 1987. Response of chloride cell numbers and gill $\mathrm{Na}+\mathrm{K}+$ ATPase activity of freshwater rainbow trout (Salmo gairdneri Richardson) to salt feeding. Aquaculture, 61, 41-48.

Suquet C., 1991. Les consommateurs français et la truite. Pisc. Fr., 104, 11-18.

\section{Summary}

The zootechnical and socio-economical potential impacts of the use of $\mathrm{rtGH}$ in salmon farming.

Salmonids (trout and salmon) are the main pisciculture production of western Europe. Animal biotechnologies affecting salmoniculture concern three areas: genetic manipulation (triploidy to produce sterile fish), gene transfer (to produce transgenic fish resistant to infectious diseases) and recombinant peptides (recombinant vaccine against viral diseases, recombinant trout growth hormone -rtGH-).

rtGH has two main biological effects: growth stimulation especially in cold water and positive impact on the adaptation of juveniles to sea water. Chronic treatment with rtGH can substantially increase the production of the main types of trout farms. However it could only really be used in high technology farms which practice water oxygenation, photoperiodic control of the spaw. ning date and computerized fish stock management. A simulation of the effects of a single treatment by injection to prepare young salmon for transfer to the sea shows that autumn transfer of treated young salmon modifies the selling period without increasing the production. However if the farmer transfers an initial group of fish treated in the autumn and a second group of fish naturally smolted in the spring, production increases by $20 \%$ and, more importantly, the selling period is extended.
The profitability of portion trout production would appear to be increased, and considering the production phase only, it does not seem that diversification towards fillet trout or the large trout would improve fish farm profitability. Although it seems that the adoption of rtGH would result in collective benefits in the long term, shared by producers and consumers, the transient phase is difficult. The difference between success and rejection is very small. The latter would lead to the reorganisation of the branch. The strategy for success would appear to involve diversification and improvements to the branch image. Even so some effects on the structure of the branch should be expected, and some producers will benefit from the surplus more than others.

Taking the concept of need into account for salmon and trout farming, rtGH has potential which cannot be neglected (better use of raw materials, reduced pollution) and also risks (bad product image, overproduction, impact on the structure of the profession). If its innocuousness can be demonstrated, it should be introduceded gradually and be accompanied by measures encouraging quality (label).

MAISSE G., BONNIEUX F., FAUCONNEAU B., FAURE A., GLOAGUEN Y., LE BAIL P.Y., PRUNET P., RAINELLI P., 1993. Impacts zootechnique et socio-économique potentiels d'une éventuelle utilisation de la rtGH en salmoniculture. INRA Prod. Anim., 6 (3), 167-183. 